\title{
Syndromes Associated with Intracranial Tumours: A Paediatric Neurosurgeon's Perspective
}

\author{
Adrianna Ranger \\ Children's Hospital, London Health Sciences Center \\ University of Western Ontario, \\ Canada
}

\section{Introduction}

Cancer is the leading disease-related cause of death among children and adolescents(Centers for Disease Control and Prevention (CDC), 2007); and cancer involving the central nervous system (CNS) is among the most common cancers seen in infancy through adolescence, ranking either first or second only to leukaemia in Canada(Ellison et al., 2009), the USA(Linet et al., 1999;Bunin et al., 1996;Centers for Disease Control and Prevention (CDC), 2007) and Mexico(Rendón-Macías et al., 2008). In the year 2004, for example, there were 555 confirmed cases of CNS cancer-related death among children in the United States, versus 566 for leukemia, representing $25.0 \%$ and $25.5 \%$ of the total number of cancer deaths in individuals less than 20 years old(Centers for Disease Control and Prevention (CDC), 2007). Nevertheless, survival from cancer has improved dramatically over the past forty years, presumably due to a combination of improved treatments and earlier detection(Chatenoud et al., 2010).

Most CNS cancers occur sporadically, outside the context of a familial disorder or multisystemic syndrome. However, a certain percentage occurs in children who have a recognizable risk of CNS malignancy. Such cases are important for several reasons. From a research perspective, understanding risk factors for cancer brings us all closer to understanding its underlying cause or causes. In those cases where there is familial clustering, chromosomal alterations that are common to cases but not unaffected relatives lead to an improved understanding of the genetics behind neoplastic disease (Bondy et al., 1994). Perhaps first and foremost from a clinical perspective is that children and youths with a known risk of CNS malignancy may be more likely to be diagnosed earlier in the course of their disease, potentially leading to earlier treatment and, thereby, enhanced outcomes. Even outside of the potential for earlier diagnosis and treatment, in certain syndromes, the cancer itself behaves differently, sometimes tending toward better, and at other times, worse outcomes. Moreover, whereas most CNS malignancies are intracranial, with cancers primarily involving the spine much less common(Koeller et al., 2000), extracranial tumours are much more common in certain syndromes.

Another reason such malignancies are important is that syndrome-affiliated malignancies often may be multiple, sometimes involving several different tumours of the same tissue type or within the same body system; and sometimes involving malignancies ranging across 
different histological types and tissues. And, finally, patients who have CNS malignancies that occur within the context of some greater syndrome often have health problems beyond that of the malignancy, some of which may be as problematic.

This chapter reviews CNS cancers that occur within a broad range of clinical syndromes, starting with what some consider the prototype CNS tumour syndromes neurofibromatosis, types I and II. In the next section, other skin conditions that, along with neurofibromatosis, are collectively known as the phakomatoses, will be examined. These additional syndromes include disorders like tuberous sclerosis, Von Hippel-Lindau Disease and basal cell nevus syndrome. Then, other familial disorders like Li-Fraumeni syndrome, a congenital condition linked to germ-line mutations of the p53 tumour suppressor gene, and familial polyposis disorders, like Turcot syndrome, will be examined. To conclude, the author's own findings regarding the associations between CNS tumours and dyschondroplasia syndromes, in particular Ollier's disease and Maffucci's syndrome, will be discussed.

- Phakomatosis syndromes

- Neurofibromatosis (types 1 and 2, and segmental forms)

- Tuberous sclerosis

- Von Hippel-Lindau disease

- Basal cell nevus syndrome

- $\quad$ Other familial syndromes

- Li Fraumeni syndrome

- Familial polyposis syndromes (e.g., Turcot syndrome)

- Rubenstein-Taybi syndrome

- Dyschondroplasia syndromes

- Ollier's disease

- Maffucci's syndrome

Table 1. Syndromes Associated with CNS Malignancies

This discussion will focus primarily on recognizing and diagnosing both the syndrome and the tumour; and, where appropriate, on differences in the management and prognosis of such patients, relative to those who present with the same tumour alone.

\section{Phakomatosis syndromes}

The phakomatoses are characterized by the presence of pathological lesions involving the skin, eyes and central and peripheral nervous system (CNS)(Korf, 2005), all tissues of ectodermal origin. The phakamotoses otherwise share the features of being autosomal dominant, with variable expression, but high penetrance; and all involving mutations of a tumour suppressor gene. Initially conceptualized by the ophthalmologist van der Hoeve in the early nineteenth century(Van der Hoeve, 1920), they were assumed to primarily consist of three disorders: neurofibromatosis, tuberous sclerosis, and what we now know as von Hippel-Lindau syndrome. Over time, each of these three disease labels has been recognized as a collective term for multiple disorders; for example, as will be described in the next section, neurofibromatosis is not one disease, but a collection of quite distinct diseases. On occasion, two distinct phakomatosis syndromes (for example, neurofibromatosis and tuberous sclerosis) have been described in the same patient(Alaraj et al., 2007); but this is 
rare and may be the result of chance rather than some increased risk for both conditions. In terms of the current chapter, these three disorders, as well as more-recently described phakomatoses, share the property of being associated with an increased risk of malignancies involving the central and, sometimes, peripheral nervous system.

\subsection{Neurofibromatosis}

Neurofibromatosis (NF) is the most common of all the phakomatosis syndromes, having been initially described by Frederick von Recklinghausen in the year 1882(Crump, 1981). Also initially called von Recklinghausen's disease, the disorder received public attention in the highly-acclaimed 1981 movie, The Elephant Man, which portrayed the life of Joseph Merrick (who was erroneously called John in the film); though some controversy exists as to whether Merrick truly suffered from neurofibromatosis, another condition called Proteus syndrome, or some combination of the two(Legendre et al., 2011). For the purposes of this chapter, what is most significant is that, whereas CNS tumours are the rule in both types of neurofibromatosis, Proteus Syndrome generally is not associated with CNS tumours(Satter, 2007). Proteus syndrome is also much less common than neurofibromatosis, with a prevalence of less than one in one million(Legendre et al., 2011).

In fact, neurofibromatosis is now recognized not to be one, but at least two distinct disorders: neurofibromatosis type 1 (NF-1) and neurofibromatosis type 2 (NF-2)(Ferner, 2007). Each of these two syndromes has its own diagnostic criteria that are very different; and whereas the characteristic lesion in NF-1 is the neurofibroma, the characteristic lesion in NF-2 is a peripheral nerve Schwannoma or neurolemoma(Pearce, 2003;Ferner, 2007;LuEmerson and Plotkin, 2009a;Lu-Emerson and Plotkin, 2009b). Neurofibromatosis has been further subcategorized beyond just neurofibromatosis types 1 and 2, into milder and more severe forms of NF-2 (Gardner syndrome and Wishart or Lee-Abbott Syndrome, respectively); segmental NF-1 and NF-2; and other variants of NF, including mixed NF. All forms of the disease appear to be autosomal dominant, though they are phenotypically highly variable, in terms of the presenting features and syndrome severity, even within a given family and when comparing monozygotic twins, suggesting the involvement of other disease-modifying genes and/or additional non-hereditary influences like second hit somatic events, environmental agents, epigenetic modification, and post-zygotic mutations(Rieley et al., 2011). This makes it difficult to advise parents regarding the risk to their future offspring, because a parent with very mild disease may have a child with severe involvement, or vice versa.

\subsubsection{Neurofibromatosis type 1}

Neurofibromatosis type 1 (NF-1) is the most common form of disease, affecting one in roughly 2500 to 5000 live births(Evans et al., 2010;Ferner et al., 2007;Legendre et al., 2011). This renders it more than ten times more common than NF-2(Evans et al., 2010;Ferner et al., 2007). Though autosomal dominant, up to $50 \%$ of cases arise spontaneously from a gene mutation that occurs on chromosome 17q11.2, which encodes for a large protein called neurofibromin (Evans et al., 2010;Legendre et al., 2011). This NF-1 gene is a classical tumour suppressor gene, with tumour growth requiring the loss of BOTH alleles. Neurofibromatosis type 1 has a classical combination of clinical signs(Ferner, 2010), for which the mnemonic CHANSOR has been used. These signs include Café au lait macules; Hamartomas of the iris (called Lisch nodules); Axillary and Inguinal Freckling; 
Neurofibromas; Skeletal lesions - like sphenoid wing dysplasia and thinning of long bone cortices; Optic gliomas; and in increased Risk of other CNS and systemic tumours. The disorder is diagnosed using National Institutes of Health (NIH) Consensus Criteria for the Diagnosis of NF-1(Ferner et al., 2007).

A diagnosis of NF-1 requires that at least TWO of the following be documented within a given patient:

- $\quad$ SIX or more café au lait spots with a maximum diameter

- $\quad>5 \mathrm{~mm}$ in pre-pubertal patients

- $\quad>15 \mathrm{~mm}$ in post-pubertal patients

- TWO or more neurofibromas of any type, or one plexiform neurofibroma

- Freckling in the axillary or inguinal areas

- An optic glioma

- TWO or more Lisch nodules

- A characteristic skeletal lesion, like

- Sphenoid wing dysplasia

- Thinning of long bone cortex, with or without pseudoarthrosis

- $\quad$ A first-degree relative (i.e., parent, sibling, or child) with confirmed NF-1

Table 2. National Institutes of Health (NIH) Consensus Criteria for the Diagnosis of NF-1

The requirement for no fewer than two of these findings means that NF-1 often only is confirmed after some passage of time, since certain features, like Lisch nodules, may not be present in infancy. Consequently, only about half $(54 \%)$ of children meet the diagnostic criteria for NF-1 by the age of one year. This number rises to $90 \%$ by 7 years; and virtually $100 \%$ of cases are diagnosed by 20 years old(DeBella et al., 2000). The Committee on Genetics of the American Academy of Pediatrics has published guidelines for the baseline/screening and follow-up evaluations of confirmed or presumed NF-1(Hersh and American Academy of Pediatrics Committee on Genetics, 2008).

- An annual physical examination, including thorough skin and neurological exams

- Annual eye exams

- Magnetic resonance imaging (MRI) of the head for

- Children diagnosed BEFORE age 5

- Children with NEW neurological deficits, vision loss or endocrinopathy

- MRI of the spine and plain X-rays for

- Children with scoliosis

- Children with back pain, radiculopathy, or long tract signs referable to the spine

- Neuropsychological and developmental testing for

- Children with learning, speech or social difficulties OR impaired motor skills

- Genetic counselling for the family

- At diagnosis and as needed, on an ongoing basis.

Table 3. Published Committee on Genetics of the American Academy of Pediatrics guidelines for the baseline/screening and follow-up of confirmed or presumed NF-1

Roughly 5\% of NF-1 cases are segmental, in that they involve only segments of the body(Sezer et al., 2006). Such cases usually are the result of mosaicism, with mutations in the 
NF-1 gene occurring AFTER fertilization, within the developing embryo(Morais et al., 2010). Such mutations are not necessarily transmissible. For example, if gonadal progenitors are spared, the transmission risk is virtually zero. If, on the other hand, gonadal progenitors are affected, the risk of transmission to the next generation ranges from near zero to $50 \%$, depending upon the percentage of gonadal cells involved. Phenotypically, one not atypical presentation of segmental NF-1 is café au lait spots affecting one limb or one side of the body and Lisch nodules in the ipsilateral eye(Morais et al., 2010;Mansur et al., 2011); others have been described with multiple localized cutaneous neurofibromas in the absence of all other sequelae(Arfan-ul-Bari, 2003). Serious sequelae, like malignancy, have been reported, but appear to be rare(Dang and Cohen, 2010).

\subsubsection{Neurofibromatosis type 2}

Neurofibromatosis type 2 (NF-2) is much less common than NF-1, with a prevalence that has been estimated as roughly one in 25,000 to 50,000(Ferner, 2010;Evans et al., 2010;Ferner et al., 2007). Although it shares the same name, it is entirely different than NF-1, in terms of the underlying cause, its presentation, its characteristic lesion, and its course(Baser et al., 2003;Bance and Ramsden, 1999).

Typically, NF-2 is caused by a mutation affecting chromosome 22q12 and the gene product merlin (a moesin-, erzin-, and radixin-like protein), which sometimes is called schwannomin. Merlin encodes for a polypeptide that may affect cell growth and motility; more interesting, in terms of its presence in NF-2, is that it is a tumour inhibitor that often is absent in brain tumours(Evans, 1999;Fontaine et al., 1991b;Fontaine et al., 1991a). In addition, the same chromosomal abnormality is found in spontaneous spinal schwannomas, which suggests that a single location causes Schwann cell tumour growth(Jacoby et al., 1999).

Clinically, NF-2 is a combination of features that always entails at least one eighth cranial nerve (CN-VIII) neurilemoma, in addition to a variety of other tumours (e.g., neurofibromas, meningiomas, gliomas, neurilemomas), juvenile posterior sub-capsular cataracts, and occasional other lesions, like café au lait spots. Like NF-1, it is diagnosed using NIH Consensus Criteria, initially proposed in 1988(Neurofibromatosis Conference Statement, 1988), but modified in 1997(Gutmann et al., 1997). To meet these most recent criteria, for either definite or presumptive NF-2, a person must have:

- $\quad$ Definite diagnosis of NF2

- The patient has bilateral CN VIII Schwannomas on MRI or CT scan (no biopsy necessary)

- The patient has a first-degree relative with NF2 AND personally has either unilateral early-onset (age $<30$ years) CN VIII Schwannoma or any 2 of the following:

- Meningioma

- Glioma

- Schwannoma

- Juvenile posterior subcapsular lenticular opacity (juvenile cortical cataract)

- $\quad$ Presumptive diagnosis of NF2

- The patient has early-onset (age <30 years) unilateral CN VIII Schwannomas detected on MRI or CT scan; AND one of the following:

- Meningioma 
- Glioma

- Schwannoma

- Juvenile posterior subcapsular lenticular opacity

- The patient has $>2$ meningiomas and a unilateral CN VIII Schwannoma, OR one of the following:

- Glioma

- Schwannoma

- Juvenile posterior subcapsular lenticular opacity

Table 4. Modified NIH Consensus Criteria for Neurofibromatosis type 2

As for NF-1, the diagnosis of NF-2 may be suspected for some time before being confirmed, given that cranial nerve VIII (acoustic) Schwannomas may present unilaterally, with the other side only becoming affected considerably later. It has been estimated, for example, that roughly $10 \%$ of individuals presenting with a unilateral acoustic Schwannoma ultimately will be diagnosed as having NF-2, a percentage high enough to warrant concern, but too low to allow for any sort of prediction(Evans et al., 2007). Similarly, juvenile cortical cataracts may antedate the confirmation of any other lesion(s). In fact, the somewhat elusive nature of both NF-1 and NF-2 (given that lesions may be small and subclinical, and/or family histories unobtainable) make it somewhat difficult to estimate the true prevalence of these disorders. What is clear is that the presentation especially of a young patient with any of the lesions described in the preceding paragraphs warrants somewhat heightened vigilance. Consequently, also as for NF-1, the Committee on Genetics of the American Academy of Pediatrics has published guidelines for the baseline screening and follow-up evaluations of confirmed or presumed NF-2, which include:

- Neurological exam

- $\quad$ Eye exam

- Audiogram

- $\quad$ MRI of head and spine

- Genetic counselling for the family, at diagnosis and as needed, on an ongoing basis.

Table 5. Committee on Genetics of the American Academy of Pediatrics guidelines for the baseline/screening and follow-up of confirmed or presumed NF-2

Finally, as for NF-1, NF-2 might present in a segmental form, though it is less well defined, and whether or not it truly exists remains somewhat controversial. Segmental NF-2 has been defined as multiple discrete neurilemomas in peripheral nerves within an extremity without any central features of NF-2. In general, segmental forms of NF-1 and, especially, NF-2 are less problematic than systemic disease, including fewer of the associated features(Hager et al., 1997). This said, some cases of segmental NF-1 can be extremely disfiguring, and malignancies have been reported(Dang and Cohen, 2010).

\subsubsection{Neurological manifestations of NF-1 AND NF-2}

All forms of neurofibromatosis, and especially neurofibromatosis type 1, are associated with numerous non-neurological, as well as neurological signs and symptoms. But it is beyond the scope of this chapter to discuss these, as they have been well described elsewhere(Hersh and American Academy of Pediatrics Committee on Genetics, 2008;Committee on Genetics, 1995;Lu-Emerson and Plotkin, 2009a;Lu-Emerson and Plotkin, 2009b). 


\subsubsection{Neurological manifestations of neurofibromatosis type 1}

\subsection{Cognitive impairment}

Various degrees and forms of intellectual and social impairment are common in those with NF, affecting up to fifty percent of patients(Ferner, 2007;Ferner, 2010;Ferner et al., 2007;Hersh and American Academy of Pediatrics Committee on Genetics, 2008; Lopes Ferraz Filho et al., 2008;Committee on Genetics, 1995;NF1 Cognitive Disorders Task Force., 1997;LuEmerson and Plotkin, 2009a;Huson et al., 1988;Rieley et al., 2011). Specific abnormalities that have been noted include mental retardation, learning disabilities, and speech disorders(Arun and Gutmann, 2004;Lu-Emerson and Plotkin, 2009a;Rieley et al., 2011;North et al., 1997).

Of these, learning disabilities are the most common, present in roughly one third to one half of patients(North et al., 1995;Denckla et al., 1996). Mental retardation, once thought to be almost ubiquitous in neurofibromatosis(Crowe et al., 1956), in fact only affects less than five percent(North et al., 1997). The etiology of these impairments may be multi-factorial, including seizures; but there is some, albeit conflicting(Hyman et al., 2003), evidence that cognitive impairment and/or the learning disabilities correlate with focal hyper-intensities that are present on magnetic resonance images(NF1 Cognitive Disorders Task Force., 1997; North et al., 1994;Joy et al., 1995). These areas of focal hyper-intensity are known as unidentified bright objects.

\subsection{Unidentified Bright Objects (UBOs)}

Of the myriad of neurological lesions that can be seen in patients with NF-1, unidentified bright objects (UBOs) are, by far, the most common lesion seen on MRI(Lopes Ferraz Filho et al., 2008). They are characterized as foci of increased signal on T2-weighted images in the absence of any mass effect, accompanied by changes on T1-weighted images and contrast enhancement. Their appearance on MR spectroscopy is different than normal brain and neoplasms. What they actually represent remains unknown, however, as well as whether or not they have any clinical relevance. There is some evidence that they correlate with learning disabilities(NF1 Cognitive Disorders Task Force., 1997), but published evidence is conflicting. In general, UBOs are considered benign. Atypical lesions generally are deemed to require further work-up, to rule out some other potentially-relevant lesion; but UBOs typically are merely noted and left alone. Left alone, many UBOs regress spontaneously over time. Lesions that correlate with neurological symptoms and new lesions in older patients require more extensive work-up.

\subsection{Optic-hypothalamic glioma}

Optic-hypothalamic gliomas comprise the second most common imaging abnormality seen in NF-1, being detectable in roughly $15 \%$ of NF-1 patients. In 1958, Dodge et al published a classification scheme for these lesions, with lesions allocated to one of three main categories dependent upon the extent of the tumour(Dodge et al., 1958). In essence, lesions were categorized into those involving just the optic nerve(s), lesions also involving the optic chiasm, and lesions extending all the way into the hypothalamus. These descriptions are expanded somewhat in Table 6.

Vision loss is characteristic of all categories of lesion(Massimi et al., 2007), but it often only is diagnosed late in younger children, who will not complain of decreased vision until losses are severe. Loss of vision usually progresses slowly, with sudden visual loss reported, but 
quite uncommon(Valdueza et al., 1995;Giuffré et al., 1982). Not uncommon signs with optic nerve gliomas are exophthalmos, optic nerve atrophy, painless ocular proptosis, papilledema, nystagmus, strabismus and conjunctival redness(Massimi et al., 2007). Optic nerve atrophy and/or papilledema, nystagmus and visual field defects are more classic for chiasmic lesions, the visual field defects often incongruous due to the irregular infiltration of the chiasm with tumour.

- Mild thickening of one or both optic nerves

- Sometimes is a low-grade glioma

- Sometimes is hyperplasia of the optic nerve sheath

- Globular thickening of the optic nerves and chiasm

- A large mass lesion involving the optic chiasm and hypothalamus

Table 6. Variants of optic-hypothalamic gliomas

Lesions that also involve the hypothalamus generally present with a more complicated clinical picture, that may include hydrocephalus (due to foramina of Monroe obstruction); various endocrinopathies (especially growth hormone deficiency and precocious puberty); diencephalic syndrome, characterized by nystagmus and profound emaciation, despite normal caloric intake, and only subtle deterioration of muscles, level of alertness, and hyperkinesis (Poussaint et al., 1997); and other neurological deficits like hemiparesis or ataxia.

Management is somewhat controversial, though there is evidence that, though an aggressive lesion in children (often infants) without NF-1, the course is much more indolent in neurofibromatosis(Massimi et al., 2007; Oh et al., 2011). Newer imaging techniques now allow for the detection of asymptomatic lesions and, among those with NF-1, many lesions progress slowly, if at all. The major difficulty is that, once vision is lost, blindness is irreparable. This is particularly catastrophic in those with bilateral or chiasmic lesions, because the blindness will involve both eyes.

Monitoring of optic-hypothalamic gliomas in children who are less than 5 years old is particularly problematic, because they often experience considerable vision loss before anything is detected. However, no firm or universally-accepted guidelines exist for monitoring. Some doctors advise annual MRIs. Meanwhile, others recommend annual neurological and ophthalmological exams, with MRIs limited to those patients who have new symptoms or findings.

Treatment is likewise controversial and lacking firm guidelines(Massimi et al., 2007). Surgery generally is restricted to those patients in whom only a single optic nerve is involved and severe vision loss already exists. It is avoided in patients with bilateral lesions or lesions involving the optic chiasm, because this generally results in total blindness. Radiation usually is effective, but it is not advised in younger children because radiation often causes significant loss of cognitive and endocrine function(Ellenberg et al., 2009;Boman et al., 2009). It also increases the risk of intracranial malignancies and vasculopathies, like moyamoya disease. Chemotherapy also is often effective, and typically selected for younger children, due to the risk of radiation-induced cognitive deficits mentioned earlier(Massimi $e t$ al., 2007). In general, combination therapy is used, involving two or more drugs. Unfortunately, chemotherapy itself is associated with an increased risk of secondary malignancies, like leukemia. 
As stated earlier, those who have optic-hypothalamic gliomas in the context of NF-1 generally have a much more indolent course than those in whom NF-1 does not exist(Massimi et al., 2007;Oh et al., 2011). This said, the prognosis is quite variable, depending upon the lesion, and may be better than for those with pure optic gliomas (again, in the absence of NF-1).

\subsection{Gliomas of the cerebral and cerebellar hemispheres}

In NF-1, hemispheric and cerebellar gliomas are less common than lesions involving the optic tract(Hottinger and Khakoo, 2009a). Most are benign or only exhibit low-grade malignant potential; but all grades of malignancy have been reported(Hottinger and Khakoo, 2009a). They differ in appearance from the UBOs mentioned earlier, in that there generally is a mass effect, and the signal on T1-weighted images is decreased, not increased. Most are resectable. Consequently, management usually starts with surgical excision. If total excision is achieved and the lesion is low-grade, monitoring may be all that is required. Partial excisions usually require adjuvant radiation therapy and/or chemotherapy(Hottinger and Khakoo, 2009a); though, as stated earlier in this chapter, radiation generally is avoided or delayed for as long as possible in younger children, especially those who are less than 3 years old, because of the risk of radiation-induced cognitive deficits. Recurrence is managed as for similar lesions in patients without neurofibromatosis.

\subsection{Brainstem gliomas}

Brainstem gliomas comprise a heterogeneous group of lesions, with at least three main subtypes: (1) a diffuse area of brainstem enlargement; (2) focal enhancing nodules with or without cystic areas; and (3) peri-aqueductal gliomas. All subtypes generally have a very indolent course. Most do not require treatment, though MRI monitoring is indicated until their indolent course is confirmed. Some lesions regress on their own(Hottinger and Khakoo, 2009a).

When there is a diffuse area of brainstem enlargement, it is somewhat similar in appearance to UBOs, except that a mass effect usually is evident. Such lesions also typically are quite a bit larger than most UBOs. Like UBOs, they exhibit abnormal signals on T1-weighted images. What the diffuse enlargement represents is controversial. Presumed to be gliomas, they have a more indolent course than brainstem gliomas seen outside of NF-1, such that adjuvant treatment only is required in the minority of patients whose lesions progress. However, ongoing monitoring is required to detect the few who do progress, before neurological deficits ensue, which often are irreversible. Rarely, these gliomas progress to more malignant forms of astrocytoma, including glioblastoma(Leonard et al., 2006;Hottinger and Khakoo, 2009a).

The focal enhancing nodules, with or without cystic areas, generally are thought to represent pilocytic astrocytomas, given their imaging characteristics. Like pilocytic astrocytomas elsewhere, they generally are indolent; but their course is unpredictable and the brainstem so susceptible to major deficits, relative to the cerebral hemispheres, that ongoing monitoring is required. Small, focal intrinsic lesions may enlarge and then regress spontaneously. Exophytic tumours often are more aggressive and require treatment.

Periaqueductal gliomas occur adjacent to the aqueduct of Sylvius between the $3^{\text {rd }}$ and $4^{\text {th }}$ ventricles in the midbrain. They typically manifest with late-onset aqueductal stenosis, leading to hydrocephalus. Presumably, they represent low-grade gliomas or glial 
hamartomas, and typically are indolent. However, because of their location, shunting often is necessary. Resection is usually not necessary for any of the brainstem gliomas seen in NF1(Hottinger and Khakoo, 2009a;Leonard et al., 2006).

\subsection{Neurofibromas}

Neurofibromas are one of the hallmark lesions of NF-1, occurring both in paraspinal areas and in peripheral nerves(Ferner, 2010;Hersh and American Academy of Pediatrics Committee on Genetics, 2008;Lu-Emerson and Plotkin, 2009a). They are histologically distinct from the neurilemomas that are the hallmark of NF-2, being composed of Schwann cells, fibroblasts, mast cells, axons and abundant extracellular matrix, with both myelinated and unmyelinated zones(Lu-Emerson and Plotkin, 2009a). Neurofibromas within the central nervous system are best visualized by MRI, which can document each lesion's size, pattern of growth, and proximity to adjacent structures, like nerves and other tissues. These tumours may be few in number or seemingly everywhere. They can be small or grow to enormous sizes that may be extremely and tragically disfiguring. Conventional wisdom states that the more cutaneous (external) lesions there are, the fewer lesions there will be in deeper (internal) tissues; but this is not necessarily the case.

Neurofibromas can be subdivided in several ways. One way is to subdivide them, according to their pattern of growth, into fusiform and plexiform lesions. Fusiform lesions are discrete lesions that involve a well-circumscribed area of a single nerve. As such, they generally are easy to resect, when necessary or indicated. In contrast, plexiform lesions often are found in nerve trunks and extend over long distances, diffusely invading the nerve tissue(Korf, 1999). They also are highly vascular and induce diffuse hypertrophy of adjacent connective tissues. Because they are so extensive and invasive, they are virtually impossible to resect without causing major neurological deficits (Hottinger and Khakoo, 2009a;Korf, 1999). Moreover, though incidence estimates vary, at least two percent of neurofibromatosis patients experience malignant transformation of a neurofibroma into a neurofibrosarcoma (Woodruff, 1999), and plexiform neurofibromas generally are perceived to be more likely to do this, with a risk as high as ten percent per lesion(Hottinger and Khakoo, 2009a).

Another way to categorize neurofibromas is by their location, into subcutaneous, peripheral nerve, plexus, paraspinal, craniofacial, and visceral lesions.

Subcutaneous neurofibromas (NFs) can be fusiform or plexiform(Hottinger and Khakoo, 2009a). Both types tend to recur after resection. Consequently, resection usually is limited to lesions that are cosmetically intolerable, unacceptably painful, growing rapidly, prone to irritation due to their location (e.g., at the patient's beltline), or undergoing malignant change.

Peripheral nerve NFs may be asymptomatic. They can, however, produce symptoms if they irritate the involved nerve, resulting in pain, paresthesias, and/or other neurological dysfunction. As stated above, they tend to be fusiform, rather than plexiform. Hence, resection generally is feasible without producing major neurological deficits if not all the nerve fascicles are involved, by starting at the proximal and distal poles of the tumour and identifying all the fascicles from which the tumour arises. If all the fascicles are involved, en bloc resection often does result in major deficits, so a subtotal resection must be performed. Follow-up of any residual tumour is necessary because approximately $15 \%$ undergo malignant transformation.

Plexus NFs are plexiform and, consequently, virtually always non-resectable without causing major neurological deficits. Resection generally is limited to tumours with evidence 
of malignant transformation or those causing intractable severe symptoms from pain or compression of adjacent structures. Many actually run an indolent course and need only be followed. Various chemotherapy protocols are being tested for those with progressive neurological impairment.

Paraspinal NFs usually are fusiform or nodular lesions that involve nerve roots as they enter the spinal canal. They occasionally involve multiple nerve roots; there even are reported cases where ALL the nerve roots were found to be involved. Generally, these lesions are slowly progressive, if at all. Monitoring often is all that is required, and there is considerable debate as to whether routine imaging even is needed, versus clinical examination alone(Khong et al., 2003). However, some do cause progressive spinal encroachment such that surgical resection is indicated(Sarica et al., 2008). When resection is necessary, various surgical approaches are used, depending on the spinal level and the tumour's relationship to surrounding paraspinal anatomy, to access and resect these tumours(Cherqui et al., 2007).

Craniofacial NFs typically are plexiform lesions that involve peripheral nerves of the face(Greig et al., 2009;Baujat et al., 2006;Visrutaratna et al., 2004;Jacquemin et al., 2003;Park et al., 2002;Jackson, 2001). Either the tumour itself or surgery to resect it can compromise the facial nerve, leading to facial paralysis and resultant cosmetic deformity. The lesions also can become massive, resulting in horrific cosmetic deformity(Greig et al., 2009;Park et al., 2002). Many involve the orbit, where they can be extremely invasive and destructive; and sometimes extend intra-cranially (Jacquemin et al., 2003). Resection of orbital lesions often requires enucleation; consequently, if they are stable, orbital lesions are usually just monitored closely.

Finally, visceral NFs tend to be plexiform and, hence, cannot be completely resected. They may occur in almost any tissue (e.g., bladder, the gastrointestinal tract), where symptoms relate to their location and size(Cheng et al., 1999;Kaefer et al., 1997;Hahn et al., 1992). Malignant transformation is a recognized, long-term risk.

\subsubsection{Neurological manifestations of neurofibromatosis type 2}

\subsection{Vestibular neurolemomas}

Vestibular neurolemomas are tumours of the eighth cranial nerve (CN-VIII) that occur in roughly $95 \%$ of patients with NF-2, often bilaterally(Ferner, 2010;Lu-Emerson and Plotkin, $2009 \mathrm{~b})$. They are diagnostic of NF-2 when bilateral. Typically, these lesions present in late adolescence or adulthood, but they can be seen in children. They should be suspected in any patient with a posterior cataract and multiple spinal cord or peripheral nerve tumours, when in the absence of café au lait spots or Lisch nodules. In such a patient, an MRI of the head clearly is indicated to rule out NF-2. In fact, the cataract could be a red herring; if the MRI shows an optic glioma, NF-1 should be considered.

Magnetic resonance imaging is the optimum screening tool for these lesions(Lu-Emerson and Plotkin, 2009b), because it is relatively sensitive at detecting them, even when they are asymptomatic. Symptomatic tumours in childhood suggest a more aggressive course. If a vestibular neurolemoma is, or bilateral neurolemomas are present, regular hearing tests are indicated, because of the risk of progressive bilateral hearing loss.

The primary goals of treatment are, first of all, to preserve hearing, recognizing that unilateral disease may become bilateral later on; and second, to prevent brainstem dysfunction or frank damage secondary to compression by tumour. However, the best way to achieve these two objectives remains both unproven and controversial. Significant 
brainstem compression is an indication for immediate surgical resection, despite the risk of lost hearing. However, if the tumour is small and not compressing the brainstem, opinions vary. Some recommend early surgery to remove tumours while small, lowering the risk of post-operative hearing loss; but the course of these tumours is variable. Hence, others recommend a wait-and-see approach, delaying surgery for as long as possible. The risk of this latter approach is that en bloc surgery ultimately may be necessary, ensuring deafness in that ear, and placing the adjacent facial nerve (CN-VII) at risk.

Stereotactic surgery MAY reduce the risk of deafness; and, if deafness occurs, it tends to be delayed one to two years, allowing for the patient to learn sign language and/or lip reading. However, the benefits of this approach over others remain unproven. Another approach is partial (sub-capsular) resection, leaving some residual tumour adherent to the auditory and facial nerves to reduce the risk of injury to both; however, residual tumour may grow and become problematic at some later date.

Especially in those with bilateral lesions, learning sign language or how to lip read ultimately may prove beneficial. And the placement of a cochlear or auditory brainstem implant may preserve some hearing, even in those who have undergone bilateral resections.

\subsection{Intracranial meningiomas}

Intracranial meningiomas are found in approximately $50 \%$ of patients with NF-2(LuEmerson and Plotkin, 2009b). They can occur singly, but commonly there are multiple lesions in a given patient with NF-2. They also often occur along with one or more nonauditory cranial nerve neurolemomas. They tend to be more aggressive in children versus adults with NF-2. As with non-auditory cranial nerve neurolemomas, because they often are multiple, it is not unusual for surgery to be deferred.

\subsection{Meningioangiomatosis}

Meningioangiomatosis is a rare, benign, focal lesion of the leptomeninges and underlying cerebral cortex, which is characterized by leptomeningeal and meningovascular proliferation(Omeis et al., 2006;Deb et al., 2006). Histologically, it appears as hamartomatous proliferation of capillary-sized vessels, meningothelial cells, and fibroblasts within cerebral cortex. It may occur in either the presence or absence of an adjacent meningioma. Though sporadic cases have been reported, meningioangiomatosis most often occurs in patients with NF-2. As with most neurofibromatosis lesions, they can be multifocal, especially in NF-2. Though histologically benign, they can produce seizures(Jallo et al., 2005), though this is more common in sporadic than in NF-2 cases(Omeis et al., 2006).

In cases of intractable seizures, resection is indicated(Jallo et al., 2005). At least one case of sudden death, presumably secondary to a fatal seizure, has been reported involving a previously-asymptomatic 13-year old boy(Wixom et al., 2005).

\subsection{Non-vestibular cranial nerve neurolemomas}

Non-vestibular cranial nerve neurolemomas are found in more than $30 \%$ of NF-2 patients. Like auditory neurilemomas, they usually are benign, but their course is more unpredictable. Some grow very slowly, if at all, and cause no problems. Others grow rapidly and are quite problematic, both due to damage of the involved nerve and because of their mass effect. And, on occasion, malignant transformation of a non-vestibular neurolemoma has been reported(Hanada et al., 1982). Because they often are multifocal, surgery usually is deferred unless they are unacceptably symptomatic, endangering function, or growing rapidly. 


\subsection{Intraparenchymal gliomas}

As a rule, spinal lesions are more common in NF-2 than in NF1, while brain lesions are less common in NF-2 than NF-1. And ependymomas are the most common malignancy in NF-2, versus astrocytomas in NF-1(Lu-Emerson and Plotkin, 2009a;Hottinger and Khakoo, 2009a;Lu-Emerson and Plotkin, 2009b). As opposed to astrocytomas, which rapidly invade surrounding neural tissue, sending multiple tumour fronds in all directions, ependymomas usually are well-circumscribed, and therefore often quite resectable. Their surgical and postoperative management (like the use of adjuvant therapy) is the same as for intramedullary spinal tumours in patients without neurofibromatosis.

\subsection{Extracranial neurilemomas and meningiomas}

Benign intraspinal tumours of the nerve sheath or meningeal cells are more common in NF2 than in the general population, though still rare. In NF-2, however, they often are multiple, occurring at many different spine levels. As they are when they are intra-cranial, both neurilemomas and meningiomas are well-circumscribed tumours that displace, rather than invade adjacent tissues; and most grow slowly(Lu-Emerson and Plotkin, 2009b;Zhang et al., 2007). They also can occlude up to $90 \%$ of the spinal canal before neurological deficits occur. Hence, most remain asymptomatic for years. However, once deficits start to appear, minimal growth can cause significant reductions in function. Surgical outcomes generally are better if such tumours are removed before neurological dysfunction is detected. Management, therefore, consists of close monitoring with repeat neurological exams and MRI; and surgical resection before neurological function starts to deteriorate. Sometimes, they must be removed because of intractable, unacceptable pain. Because they generally involve a single nerve fascicle, they often can be resected without significant neurological deterioration, if any at all(Lu-Emerson and Plotkin, 2009b;Zhang et al., 2007).

\subsection{Neurofibromas}

In NF-2, neurofibromas are much as they are in NF-1, except that they are much less common(Lu-Emerson and Plotkin, 2009b). Because many neurofibromas, especially plexiform lesions, are not as well-encapsulated as neurilemomas, they are more problematic, and more difficult to resect. Consequently, surgical outcomes generally are worse than for neurilemomas.

\subsubsection{Summary: Neurofibromatosis}

Neurofibromatosis is a collection of disorders, which can be systemic or segmental. Systemic neurofibromatosis types 1 and 2 are the most common and best recognized syndromes, though segmental and overlap syndromes exist. Both NF-1 and NF-2 are autosomal dominant, but spontaneous mutations are not uncommon, and there is tremendous phenotypic variability even within a given family or between twins. Type 1 is at least ten times as common as type 2 disease, with all other types less common still. The two classic forms of neurofibromatosis, NF-1 and NF-2, are very different. Whereas the characteristic lesion of NF-1 is a neurofibroma, the characteristic lesion of NF-2 is a neurilemoma, which involves either one or both auditory nerves (CN-VIII) in 95\% of cases. Both NF-1 and NF-2 are associated with numerous other CNS and peripheral nervous system tumours. These are summarized in Table 11. 
Neurofibromatosis type 1

- Non-neurological lesions:

- Skin and retinal hamartomas (café au lait spots, axillary freckling and Lisch nodules)

- Various bone abnormalities, including cortical thinning, sphenoid dysplasia, and bowing of long bones

- Segmental hypertrophy of skin, bone and subcutaneous tissues

- Hypothalamic tumours

- Neoplasms involving other body systems, including pheochromacytomas, rhabdomyosarcomas, adenocarcinomas, melanomas, non-Hodgkin's lymphomas, and lymphoblastic leukemias

- Neurological lesions

- Neurofibromas

- Neurofibrosarcoma (malignant transformation of a neurofibroma)

- Unidentified bright objects (UBOs) on MRI

- Optic-hypothalamic gliomas

- Cerebral, cerebellar and brainstem gliomas

Neurofibromatosis type 2

- Non-neurological lesions:

- Posterior subcapsular cataracts

- Neurological lesions

- Vestibular neurolemomas

- Intracranial meningiomas

- Meningioangiomatosis

- Non-vertebral cranial nerve neurolemomas

- Extracranial neurolemomas and meningiomas

- Intraparenchymal gliomas, especially of the spine

Table 7. Lesions classically associated with neurofibromatosis types 1 and 2

Both NF-1 and NF-2 are diagnosed using published diagnostic criteria that, like the syndromes themselves, are highly different from one another. The diagnostic process requires patient and family histories, detailed physical examinations (especially dermatological and neurological), and imaging studies (especially MRI). The course of many tumours and of the disease itself is often hard to predict. Most tumours are slow-growing and relatively indolent, but many have the potential to undergo malignant change and others may cause neurological impairment, either by compression or invasion. Especially in NF-1, neurofibromas can be tragically disfiguring. Management of the neurofibromatosis syndromes includes regular close monitoring; genetic counselling of families; and surgery, which typically is deferred until absolutely necessary. Surgical outcomes generally are better with NF-2 than with NF-1.

\subsection{Tuberous sclerosis (Bourneville's disease)}

Tuberous sclerosis, which also is called tuberous sclerosis complex (TSC) and Bourneville's disease, is the second most common phakomatosis syndrome, after neurofibromatosis type 1. It affects anywhere from one in 6000 to one in 30,000 people(Osborne et al., 1991;Hong et al., 2009;Morrison, 2009), with marked variations in penetrance rendering all estimates somewhat unreliable. 
Like neurofibromatosis, it initially was described by von Recklinghausen, in 1862; however, it is named after a French physician, Désiré-Magloire Bourneville, who coined the term 'sclerose tubereuse' in 1880, likening the cerebral lesions he detected at autopsy to small potatoes. The physical manifestations of tuberous sclerosis largely are due to the formation of hamartia (malformed tissue, like cortical tubers), hamartomas (like facial angiofibroma and subependymal nodules) and, very rarely, cancerous hamartoblastomas. The effect of these various lesions on the brain includes various neurological symptoms, such as seizures, developmental delay, and behavioural problems. The initially-described triad of features was epilepsy, low intelligence, and skin lesions, though the condition is now recognized to involve numerous other organ systems, as well, including the kidneys, lungs, heart and eyes. And many cases of 'low intelligence' have since been recognized as learning disabilities, autism, and pervasive development disorders, rather than low intelligence, per se(Ridler et al., 2006;Harrison and Bolton, 1997).

Tuberous sclerosis (TS) is autosomal dominant, but up to $60 \%$ of cases arise from spontaneous mutations(Orlova and Crino, 2010;Osborne et al., 1991;Morrison, 2009). Two tumour-suppressor genes, TSC-1 (tuberous sclerosis complex-1) and TSC-2, are responsible for TS. Roughly $80-90 \%$ of mutations involve TSC-2, while just $10-20 \%$ of mutations involve TSC-1(Orlova and Crino, 2010). The genetic locus for TSC-1 is chromosome 9q34, and the TSC-1 gene product is called hamartin. The genetic locus for TSC-2 is chromosome 16p13.3, and the TSC-2 gene product is called tuberin. Both hamartin and tuberin appear to have roles in cell differentiation, proliferation and migration. The disorder effects cellular differentiation, proliferation and migration during early development, leading to various diffuse hamartomas and neoplastic lesions affecting virtually every body organ(Grajkowska et al., 2010;Orlova and Crino, 2010). It can present at any age, but most commonly appears during childhood, especially late childhood.

\subsubsection{Non-neurological involvement in tuberous sclerosis}

A broad spectrum of skin lesions are associated with tuberous sclerosis, with skin lesions the most common and recognizable feature of this syndrome. They include ash-leaf spots; facial angiofibromas; lumbosacral angiofibromas (Shagreen patches); café au lait spots; periungual fibromas (Koenen tumours); forehead plaques; skin tags (molluscum fibrosum pendulum); confetti macules; and poliosis, with ash-leaf spots the most characteristic lesion, seen in $5 \%$ of the general population, but $97 \%$ of TS patients. The ash-leaf spot is a hypomelanotic macule, of variable size but up to several inches in length, which is found on the trunk and/or the buttocks. It is recognized by the axis of the leaf, which tends to line up perpendicular to the axis of the spine. This usually is the only sign of TS that is visible at birth. Because they are characterized by decreased pigmentation, a Wood's lamp may be required to see ash-leaf spots in fair-skinned individuals.

Facial angiofibromas, also called adenoma sebaceum, are reddish macules or papules, though they may appear dark brown in darker-skinned individuals. Classically, they are clustered around the nose and cheeks in a butterfly distribution, and may be mistaken for acne, especially in teenagers, except that they do not contain purulent material and, hence, cannot be drained. Histologically, they consist of blood vessels and fibrous tissue. Because they can be cosmetically displeasing, they can be removed either by dermabrasion or laser treatments(Verma et al., 2001). 
Lumbosacral angiofibromas also are called shagreen patches. These are areas of thick leathery skin that are dimpled like an orange peel, usually found on the lower back or nape of the neck. They, like ash-leaf spots, are of variable size, but can be quite sizeable. Café au lait spots are as previously described for neurofibromatosis. Periungual fibromas (Koenen tumours) are very rare in childhood, but common by middle age. They are small, fleshy tumours that grow around and under the toenails and/or fingernails. They sometimes need to be surgically removed if they enlarge or cause bleeding. Forehead plaques are as they sound: raised, discoloured areas on the forehead. Skin tags (molluscum fibrosum pendulum) are very non-specific, commonly seen in healthy individuals. Confetti macules are clusters of small, punctate, hypopigmented macules that look like confetti (hence, the name). They are fairly specific for TS, commonly found symmetrically on the limbs. Poliosis is a tuft or patch of white hair on the patient's scalp or eyelids, and patients may have several.

Intraventricular rhabdomyomas are the most common cardiac manifestation of tuberous sclerosis. These are benign tumours of striated muscle that, in TS, may be multiple. In fact, multiple tumours affecting multiple chambers are common, though most are found within the ventricles. They are detectable by echocardiography in roughly $50 \%$ of TS patients. However, their incidence ranges from up to $90 \%$ in newborns to as low as $20 \%$ in adults. They generally grow during the second half of pregnancy and regress after birth. Many disappear entirely. Alternatively, tumour size may remain constant as the heart grows, with much the same effect. Most remain asymptomatic, detected on peri-natal ultrasound after 20 weeks of gestation, and never become clinically manifest. Some produce a murmur. Potential problems include obstruction of blood flow if the tumour impedes proper valve opening; and arrhythmia. However, most cardiac complications occur before the child reaches one year old. Why they are clinically important is that this rare tumour is a strong indicator of TS in a child, especially if there is a positive family history of TS.

Kidney involvement is the second most common cause of morbidity and mortality in TS, after neurological disease. It is the most common cause of death in patients who are greater than 30 years old. A host of renal lesions exist, which include angiomyolipomas, renal cysts, renal cell carcinomas, and oncocytomas. Renal cell carcinomas are rare, relative to anygiomyolipomas and cysts, but still affect up to $3 \%$ of patients, making them considerably more common in TS patients than in the general population. Oncocytomas are a benign adenomatous hamartoma that are even more uncommon. Conversely, angiomyolipomas are indentified in 60 to $80 \%$ of TS patients. They usually are benign; but they also usually are multiple and bilateral and frequently cause haematuria. Histologically, they are composed of vascular tissue, smooth muscle, and fat. And, although benign, a lesion larger than $4 \mathrm{~cm}$ in diameter is at risk for a potentially catastrophic haemorrhage, either spontaneously or with minimal trauma. These lesions are not exclusive to TS, being found in about 1 in 300 people without TS. However, lesions in non-TS patients usually are solitary. Renal cysts can be identified in between 20 and $30 \%$ of TS patients, but they usually cause few if any problems. Having said this, $2 \%$ of TS have autosomal dominant polycystic kidney disease which commonly leads to renal failure.

Lung involvement in tuberous sclerosis usually affects women in their third and fourth decades of life, implicating some hormonal influence. The classic lesion is lymphangioleiomyomatosis (LAM), which is progressive replacement of the lung parenchyma with multiple cysts, generally measuring $2-20 \mathrm{~mm}$ in diameter, with equal involvement of all lobes. These cysts are formed by hyperplastic smooth muscle. Recent 
genetic analysis suggests that this proliferative bronchiolar smooth muscle represents monoclonal metastases from a coexisting renal angiomyolipoma. There have been cases of TSC-related LAM recurring following lung transplantation, confirming the concept of an 'external' source. The prevalence of LAM in patients with TS is roughly $1-5 \%$, making it vastly more common than the one per million prevalence observed in the general population. Nonetheless, it often is misdiagnosed as asthma, emphysema, or some other pulmonary disease. Plain radiographs reveal the superimposition of cysts, producing the reticulonodular pattern typical of interstitial lung disease. High-resolution CT is more specific for the diagnosis, and better at assessing the degree of pulmonary involvement. Prognostically, LAM is slowly progressive. It also, interestingly, tends to be associated with less severe TS, accompanied by less intellectual impairment and fewer seizures. Roughly $90 \%$ of patients with LAM remain alive 15 to 20 years after diagnosis.

Retinal phakomas, gray or yellow retinal plaques that may be single or multiple, are the classic ocular lesion seen in TS, being present in up to $87 \%$ of patients. They rarely affect vision and, hence, usually do not warrant any treatment.

\subsubsection{Neurologic involvement in tuberous sclerosis}

Neurological involvement is the most common cause of morbidity and mortality from TS, and the most common cause of death in patients under 30 years old. Problems stem from a broad variety of intra-cerebral tumours, which include cortical tubers, subependymal nodules, and subependymal giant cell astrocytomas (SEGA).

Cortical tubers can be identified in more than $80 \%$ of patients. Recall that they are what Bourneville first described, and the reason behind the disease's name. They are formed from aberrant neuronal migration during the development of the cerebral cortices, and primarily affect the frontal and parietal lobes. Although non-malignant, they are problematic, because they may result in life-long, intractable seizures. Unfortunately, resection of these tumours often does NOT lead to any major reduction in seizures, though large tumours may need to be resected due to their mass effect.

Subependymal nodules are the hallmark lesion for TS on computed tomography (CT) scans. They may be either calcified or non-calcified, and may number from one to as many as 20 lesions. Some have described their appearance on CT as looking like the drippings of a candle. They are composed of abnormal, swollen glial cells and bizarre multinucleated cells that are indeterminate, in terms of glial versus neuronal origin. There is no interposed neural tissue. These nodules have a tendency to calcify as the patient ages. More ominously, any nodule that markedly enhances and enlarges over time should be considered suspicious for transformation into a subependymal giant cell astrocytoma (SEGA).

Subependymal giant cell astrocytomas (SEGA) develop in between 5 and 15\% of TS patients(Goh et al., 2004), typically developing in the region of the foramen of Monro, where they frequently cause obstructive hydrocephalus. Though they are slow-growing and rarely undergo malignant transformation, these tumours are problematic because of their location and relative inaccessibility for resection.

Problems related to the various neurological lesions of TS include intractable seizures, which ultimately present in $97 \%$ of patients with cortical tubers and in $75 \%$ of patients with cortical tubers before one year old. Various forms of intellectual, social and behavioural impairment are other sequelae of these tumours, including autism in roughly 20 to $60 \%$, learning disabilities in about $50 \%$, and mental retardation and self-mutilation, both in roughly $10 \%$. These effects often are progressive; in fact, many neonates are neurologically 
normal. Table 8 lists the various complications related to cortical tubers and other CNS lesions in tuberous sclerosis.

- Seizures, often intractable

- Progressive intellectual impairment

- Learning disabilities

- Impaired social and communication skills

- Behavioural impairment

- Purposeful self-injury / self-mutilation

- Autism

- Hyperactivity

- Obsessive behaviours

- Obstructive hydrocephalus

- Mass effects from tumour growth

- Death, primarily from intractable seizures or SEGA-induced obstructive hydrocephalus

Table 8. Complications related to cortical tubers and other CNS lesions in tuberous sclerosis

These CNS lesions are diagnosed by various imaging techniques, including CT, CT with contrast, and MRI. Gadolinium-enhanced MRI is the most sensitive radiographic study. Electroencephalograms (EEG) are useful to document and identify the foci of seizures. The diagnosis of tuberous sclerosis as a syndrome, however, is made using published criteria that include a wide range of both major and minor criteria(Roaches et al., 1998).

Management essentially consists of monitoring and supportive measures. Magnetic resonance imaging of the head every 1-2 years is indicated to assess for tumour growth, mass effects, and impending outflow obstruction. Anti-epileptic drugs are used to control seizures, since the resection of tumours is difficult, dangerous and of uncertain benefit; surgery to control seizures rarely results in complete seizure resolution.

Surgery may be performed to relieve increased intracranial pressure and focal deficits from tumours, and hydrocephalus from obstruction, primarily at the foramen of Munro. Complete resection of intra-ventricular tumours often is difficult, if not impossible, because of their origins in the caudate nucleus and septum pellucidum. Also, though relatively avascular, the tumours invade surrounding tissue and can be quite large. Finally, incomplete resection risks tumour re-growth. Recently, rapamycin has demonstrated some promise for SEGA in patients with tuberous sclerosis(Franz et al., 2006). Overall, however, the long-term prognosis is poor. The rate of mortality is increased relative to age-matched population, with the \#1 cause of death being renal disease, and the \#1 cause of morbidity CNS disease, primarily related to seizures, cognitive impairment, and SEGA-induced obstructive hydrocephalus.

\subsection{Von Hippel-Lindau disease}

With angiomas in the eye first described by the German ophthalmologist Eugen Von Hippel in 1904, and the association between these retinal with CNS tumours first noted by the Swedish pathologist Arvid Lindau in 1927, the disease that Lindau first called 'angiomatosis of the central nervous system', and which for years was known just as Lindau syndrome, is now named for both men. Also known as retinocerebellar angiomatosis, its incidence has been estimated as roughly 1 in 31-36,000 live births(Hottinger and Khakoo, 2009b), though it 
is not usually manifested in infancy. The average age at first presentation is 26 years, and the average age at diagnosis 31 years(Hottinger and Khakoo, 2009b). Nonetheless, paediatric cases are not uncommon, and certainly seen by the paediatric neurosurgeon as a challenging disorder to treat.

Von Hippel-Lindau disease is autosomal dominant, with $97-99 \%$ of cases familial and only $1-3 \%$ occurring as a result of spontaneous mutations. It is associated with inactivation of the tumour-suppressor gene VHL (Von Hippel Lindau), which is found on chromosome 3p25(Hottinger and Khakoo, 2009b;Seizinger et al., 1988). Decreased levels of the VHL protein, which is important in a critical pathway helping cells to adapt to hypoxic stress, lead to over-expression of a hypoxia-inducible transcription factor (HIF-1) which, in turn, results in increased cell proliferation, and the over-expression of several growth factors, ultimately manifesting as multiple, multi-systemic benign and malignant tumours, which sometimes are bilateral (e.g., both eyes)(Glasker, 2005). These tumours include haemangioblastomas of the cerebellum, spine, brainstem and retina (the most common tumour identified); renal clear cell carcinomas; pheochromocytomas; pancreatic and renal cysts; endolymphatic sac tumours (ELSTs, of the petrous bone at the cerebellopontine angle)(Hassard et al., 1984); papillary cystadenomas of the epididymus or broad ligament; and haemanigiomas of the adrenal glands, liver and lungs. The diagnosis is made on clinical grounds using established, published criteria:

- $\quad$ Two or more haemangioblastomas; OR

- One haemangioblastoma PLUS some visceral lesion, like pheochromocytoma, pancreatic or renal cyst, or renal cell carcinoma; OR

- One retinal or CNS haemangioblastomas or some other visceral lesion PLUS a positive family history of CNS or visceral manifestations of the disease.

Table 9. Classification criteria for Von Hippel-Lindau disease

The disease is subdivided into various clinical subtypes, based upon genotype-phenotype correlations within families, with type 1 families having pheochromocytomas, and three sub-classes of type 2 disease, all lacking pheochromocytomas but a familial risk of other tumour typess: type $2 \mathrm{a}$, with a low familial risk of renal cell carcinoma and pancreatic tumours; type $2 \mathrm{~b}$, with a high familial risk of renal cell carcinoma and pancreatic tumours; and type 2c, with a high familial risk of isolated pheochromocytomas(Ong et al., 2007)

Central nervous system manifestations are highly prevalent(Butman et al., 2008;Richard et al., 1998), with CNS haemangioblastomas occurring in 60 to $80 \%$ of patients. Moreover, they are more likely to be multiple and present at an earlier age than when they occur sporadically, being a presenting feature in roughly $60 \%$ of VHL patients(Wanebo et al., 2003). These lesions may occur anywhere along the cranioaxial axis, but only $1 \%$ of these tumours are supratentorial(Wanebo et al., 2003). The site of lesion determines the symptoms with which the patient presents. The cerebellum and brainstem are the most common sites of haemangioblastomas in VHL syndrome(Wanebo et al., 2003), where patients present with headaches, vomiting, lethargy, dysmetria, ataxia, papilloedema, polycythemia from tumour production of erythropoietin, and/or enlarging cysts that may cause brainstem compression (solid tumours generally do not cause such compression in VHL syndrome).

Conversely, spinal haemangioblastomas present with neck, chest and back pain, sensory losses, and various signs and symptoms of cord compression depending upon tumour location. Patients with cervical haemangioblastomas typically present with neck pain, signs 
and symptoms of cord compression and, sometimes, severe infratentorial and supratentorial subarachnoid haemorrhage. Finally, retinal haemangioblastomas present with vision loss secondary to haemorrhage, exudation, and retinal detachment.

Haemangioblastomas typically are cystic, and, thus, enhance with contrast. Contrastenhanced T1-weighted MRI is largely considered the diagnostic test of choice to detect and monitor CNS lesions. The optimum treatment of CNS haemangioblastomas is complete surgical excision, whenever possible, since residual tumour may cause severe bleeding(Schimke et al., 2009). Pre-surgical endovascular embolization may reduce operative complications and morbidity; while small asymptomatic lesions may be monitored with repeat MRIs.

Alternative treatments have been developed that include gamma knife radiosurgery(Wang et al., 2005;Tago et al., 2005), which seems to be effective for small to medium-sized nodular, but not cystic lesions, which bleed. Linear-accelerator (LINAC)-based cranial stereotactic radiation therapy also has proven effective with some tumours. And multiple agents that target gene products downstream from $\mathrm{pVHL}$ and HIF-1, like platelet-derived growth factor (PDGF), have recently become available and are being tested(Hottinger and Khakoo, 2009b). Despite all these surgical advances, and the fact that haemangioblastomas are considered 'benign', the average patient succumbs in their fifth decade of life(Niemela et al., 1999), with the main causes of mortality being metastatic renal cell carcinoma and cerebellar haemangioblastomas(Hes et al., 2001;Niemela et al., 1999).

\subsection{Basal cell nevus syndrome (Gorlin-Goltz syndrome)}

As with almost all the disorders described so far in this chapter, basal cell nevus syndrome (BCNS) is autosomal dominant, the offending gene, called PTCH1, localized to chromosome $9 \mathrm{q} 31$ in about $85 \%$ of cases. The PTCH1 gene product is a trans-membrane receptor that binds to and regulates a protein called Sonic the hedgehog homolog $(\mathrm{SHH})$, one of three proteins in the mammalian signalling pathway family called 'hedgehog', and one which plays a key role in the regulation of organ development in vertebrates, including the growth of fingers and toes and the organization of the central nervous system. It also controls cell division in adult stem cells and has been implicated in oncogenesis. Mutations in the PTCH1 gene result in uncontrolled SHH activation(Thayer et al., 2003).

This rare condition, which affects roughly one in 50 to 60 thousand live births(Hottinger and Khakoo, 2009b), is characterized by multiple basal cell cancers, often presenting in adolescence. Despite the relatively innocuous-sounding name, there is a wide range of non-neurological manifestations, as listed in Table 10, including numerous other benign and malignant tumours, both non-CNS and CNS, including melanomas, leukaemia, lymphoma, lung and breast cancers, medulloblastoma and meningiomas(Shanley et al., 1994).

Odontogenic keratocysts (jaw cysts) are often the first sign of the syndrome, commonly becoming manifest early in childhood. These are cysts lined with keratinized epithelium that originate in dental lamina and locally erode all the way to the teeth, to cause dental displacement and loss, if they are not completely excised. Medulloblastomas are the most common CNS tumour, and they too present early, in roughly 3 to $5 \%$ of children with BCNS(Evans et al., 1991). The medulloblastomas seen in BCNS tend to occur earlier than in sporadic cases and often are histologically distinct from classic medulloblastomas, being defined by the presence of several prominent nodules, or 'pale islands', of tumour. These 
areas are of lower cellularity, which are reticulin-free, exhibit nuclear uniformity and are in a background of collagen-rich, highly-proliferative tumour. Desmoplastic medulloblastomas also tend to be more discrete than the classic variety and often are located in the cerebellar hemispheres. Given their location in the posterior fossa and the fact that they can become quite large, hydrocephalus is a common complication of medulloblastomas in BCNS, and may be a presenting sign.

- Multiple Nevoid Basal Cell Cancers

- Odontogenic keratocysts (jaw cysts)

- Other bone cysts

- Calcified falx cerebri / dural calcifications

- Pitting of plantar or palmar surfaces

- Congenital skeletal abnormalities including:

- Hypertelorism

- High scapulae (Sprengel's Deformity)

- Frontal bossing (that also may involve parietal area)

- Synostosis of various cranial sutures

- $\quad$ Bifid ribs

- Cleft lip and/or palate

- Eye disorders

- Colobomas

- Cataracts

- Glaucoma

- Non-CNS benign and malignant tumours

- Melanoma

- Chronic lymphocytic leukaemia

- Non-Hodgkin's lymphoma

- Lung cancer

- Breast cancer

- Myocardial fibromas

- Lyomesenteric cysts

- Ovarian fibromas and dermoids

- Rhabdomyoma

- CNS tumours

- Medulloblastoma

- Meningioma

Table 10. Clinical characteristics of basal cell nevus syndrome

Like virtually all the familial cancer syndromes, basal cell nevus syndrome is diagnosed using diagnostic criteria. More advanced imaging, like MRI or CT, is necessary for CNS tumours. Again, jaw and other bone cysts plus medulloblastomas may present before nevi on the skin, so the absence of nevi does not rule out the condition. Interestingly, a recentlydiagnosed 10-year old child was found to have café au lait spots(Balasundrum et al., 2010), emphasizing the considerable phenotypic variability evident in virtually all of the phakomatosis syndromes(Hottinger and Khakoo, 2009b). The diagnostic criteria are summarized in Table 11(Amlashi et al., 2003). 
The diagnosis is established in the presence of TWO or more major criteria or ONE major criterion plus TWO or more minor criteria:

- $\quad$ Major criteria

- Calcification of the falx cerebri

- $\quad$ Bifid or fused ribs

- Jaw cysts

- Palmar and plantar pits

- First-degree relatives with the same syndrome

- $\quad$ Minor criteria

- Medulloblastoma

- Ovarian fibroma

- Macrocephaly

- Congenital facial or skeletal abnormalities like cleft lip or palate; hypertelorism; frontal bossing; syndactyly; and radiological bone abnormalities like bridging of the sella turcica.

Table 11. 2003 Diagnostic Criteria for Basal Cell Nevus Syndrome

Treatment of BCNS is largely supportive and as for others with similar tumours, of the CNS and elsewhere. However, it is complicated by current failures to accurately predict the course of medulloblastomas, in general and in BCNS, since no histological grading system has yet been identified that accurately predicts prognosis. This is confounded further by concerns as to the potentially increased risk of radiation-induced secondary malignancies, especially in children who have the potential for very long-term survival (e.g., the child who develops secondary osteosarcoma in the radiation field for a previously-treated medulloblastoma). The general impression that medulloblastomas have a more indolent course in BCNS than otherwise has led to some to suggest that the dose of radiation can be reduced(Stavrou et al., 2001). As with many of the familial cancer syndromes described in this chapter, better understanding of the underlying genetics of cancers like medulloblastoma has led to more directed chemotherapies that hold some promise(Taipale et al., 2000).

\section{Other familial syndromes associated with pediatric CNS malignancies}

\subsection{Li-Fraumeni syndrome}

Li-Fraumeni Syndrome (LFS) is another very rare autosomal dominant disease that is caused by a germ line mutation of chromosome p53 in roughly $70 \%$ of families in which the syndrome is diagnosed(Kleihues et al., 1997). Patients exhibit an increased risk of variety of carcinomas and sarcomas, including premenopausal breast cancers, osteosarcomas, soft tissue sarcomas, acute leukaemia, cancer involving the adrenal cortex, and primitive neuroectodermal tumours (PNET) like medulloblastoma. This increased risk of a wide variety of malignancies likely stems from deactivation of p53, which normally controls apoptosis and the repair of damaged DNA.

Patients present not only with a variety of cancers, but with cancers at a very early age. The mean age at presentation in LFS patients with brain tumours is about 25 years. The diagnosis of so-called 'classic LFS' is made in any patient under 45 years who presents with a bone or soft-tissue sarcoma, plus one first-degree relative who presents with any cancer 
before age 45, plus one further first or second-degree relative of the same lineage who has had any cancer before age 45 or a sarcoma at any age(Li et al., 1988). More recently, a related syndrome, called Li-Fraumeni-like syndrome, has been described, defined as a proband with any childhood tumour or any sarcoma, brain or adrenocortical tumour before 45 years of age, who has a first- or second-degree relative with any cancer before the age of 60(Birch, 1994;Evans et al., 2008). Interestingly, whereas p53 germ-line mutations are found in $70 \%$ to $80 \%$ of families with classic Li-Fraumeni syndrome, they only are identified in between $20 \%$ and $40 \%$ of families with Li-Fraumeni-like syndrome(Hottinger and Khakoo, 2009b). The CHK2 checkpoint homolog gene, CHEK2, which is located on the long (q) arm of chromosome 22, also has been implicated in some families with classic Li-Fraumeni syndrome. Recently, mutation of another gene, which encodes for the breast cancer 2 (BRCA2) susceptibility protein, has been found with increased frequency in the non-classic syndrome(Evans et al., 2008). It should be noted that p53 mutations are rare in sporadically occurring medulloblastomas.

Overall, about $10 \%$ of LFS patients will develop a glioma before the age of 45 , and another $5 \%$ a supratentorial primitive neuroectodermal tumour (PNET), like a medulloblastoma, or choroid plexus carcinoma(Taylor et al., 2000). Since LFS is so rare, no clinical trials document the optimum treatment; but it generally is agreed that incident tumours should be treated as for sporadic cases, albeit with increased vigilance for additional tumours, both within the proband patient due to the increased risk of second cancers(Birch et al., 2001), and the family.

\subsection{Familial polyposis / Turcot syndrome}

A Canadian surgeon named Jacques Turcot is accredited with having characterized Turcot syndrome, one of the several familial polyposis syndromes associated with familial, in this case autosomal recessive, inheritance and the presence of multiple colonic adenomas and adenocarcinomas(Foulkes, 1995). An additional feature of Turcot syndrome is its association with several different neuroepithelial tumours of the central nervous system, including astrocytomas, medulloblastomas, pineoblastomas, gangliogliomas, and ependymomas(Hottinger and Khakoo, 2009b).

Turcot syndrome has been categorized into types 1 and 2, with type 1 characterized by glioblastoma, no familial adenomatous polyposis, but often hereditary non-polyposisrelated colorectal carcinoma. Germ-line mutations in a few DNA mismatch repair genes PMS2, MLH1 and MSH2 - are associated with type-1 Turcot syndrome. Interestingly, type-1 Turcot syndrome also is associated with café au lait spots(Hottinger and Khakoo, 2009b). Conversely, type-2 Turcot syndrome families have medulloblastomas as their most common CNS malignancy, and multiple adenomatous polyps that often undergo malignant transformation(Hamilton et al., 1995). Unfortunately, medulloblastomas, glioblastomas and anaplastic astrocytomas are the most common CNS tumours observed in Turcot's syndrome, the three combined accounting for $95 \%$ of all CNS tumours in these families(Paraf et al., 1997); and the latter two are inevitably fatal. In addition, they tend to occur early, with medulloblastomas typically diagnosed in children less than 10 years old, and gliomas in those under age 30(Hottinger and Khakoo, 2009b;McLaughlin et al., 1998;Jamjoom et al., 1989;Schroder et al., 1983).

As such, and because some die of metastatic colon cancer that sometimes presents quite early in childhood or the second decade of life, many die as adolescents or young adults. In one tragic case, for example, doctors in Pittsburgh reported the case of a girl who developed a medulloblastoma at the age of 5 years. Ten years later, she developed adenocarcinoma of 
the colon. Then, seven months after resection of a Dukes' C2 adenocarcinoma, she presented with a second primary CNS tumour, this time a glioblastoma multiforme(McLaughlin et al., 1998). Presumably, she died shortly thereafter from her glioblastoma.

\subsection{Rubenstein-Taybi syndrome}

Rubenstein-Taybi syndrome is an autosomal dominant disorder that is associated with numerous anatomical/functional abnormalities that include abnormal facies, microcephaly, broad thumbs, big toes and moderate to severe intellectual impairment. There also is an increased incidence of neuroepithelial tumours; in particular medulloblastomas, meningiomas, and oligodendrogliomas(Taylor et al., 2001), though other CNS tumours have been described(Burton et al., 1997). A germ-line mutation in one allele of CRE binding protein (CBP, a transcriptional co-activator for several c-AMP regulated genes) has been implicated in many cases. CBP binds to the activated form of GLI, a transcription factor that is important in the regulation of the Sonic hedgehog homolog $(\mathrm{SHH})$ that, as stated earlier, controls cell division in adult stem cells and has been implicated in oncogenesis. The GLI gene is downstream of the PTCH1 gene that is mutated in basal cell nevus syndrome.

\section{Ollier's disease and Maffucci syndrome}

Enchondromatosis, also called dyschondroplasia, is a hamartomatous proliferation of chondrocytes within the metaphysis of bone (2008). Enchondromatosis often is asymptomatic and only diagnosed as an incidental X-ray finding. On the other hand, it can lead to significant deformities, reduced bone length(Baumgart et al., 2005;Shapiro, 1982), and occasional pathologic fractures(Shapiro, 1982). Moreover, enchondromas appear to have an association with malignancy. This includes both chondrosarcomas that result from sarcomatous transformation of the enchondromas themselves, and other histologicallydistinct malignancies, including angiosarcomas, osteosacrcomas, a variety of central nervous system tumours, ovarian tumours, and various leukaemias(Ranger et al., 2009b). This association with malignancy appears to be particularly true in instances of multiple enchondromatoses, as in Ollier's disease and Maffucci's syndrome(Schwartz et al., 1987).

In 1881, an Italian pathologists named Angelo Maffucci first described a patient with enchondromatosis and venous angiomas on the skin(Maffucci, 1881), though others followed suit within a decade(Kast and von Recklinghausen, 1889). For years, the apparent 'dual discovery' of this combination of clinical findings led to the alternative use of the labels Maffucci's syndrome and Maffucci-Kast syndrome, though the latter label ultimately largely was discarded. The term Ollier's disease entered into use after 1889, when a French surgeon, Louis Léopold Ollier, described a patient with enchondromatosis in the absence of any evident vascular abnormalities(Ollier, 1899). Since then, a line largely has been drawn between those with accompanying vascular abnormalities, primarily haemangiomas, and those without. Debate continues as to whether these two 'syndromes' are distinct clinical entities, versus variations in the expression of the same disease(Mellon et al., 1988). This debate has been fuelled by the late discovery of vascular abnormalities in some patients previously considered to have Ollier's disease(Ahmed et al., 1999;Bertucci and Krafchik, 1995). Both conditions are considered very rare, with Ollier's disease having a reported prevalence of roughly one in 100,000(Silve and Jüppner, 2006); and fewer than 200 total cases of Maffucci's syndrome reported in the literature since it first was reported in 1881(Balcer et al., 1999). 
The first report of a CNS malignancy in a patient with multiple enchondromatosis was published in 1904, by Boinet, who diagnosed a chondrosarcomatous lesion of the skull base in a 37-year old gentleman with Maffucci's syndrome who was living in France(Boinet, 1904). Since that time, 45 additional patients with either Ollier's disease (OD) or Maffucci's syndrome (MS) and some form of intracranial malignancy have been reported in the medical literature, ranging from 6 to 58 years old(Ranger et al., 2009a).

The combination of enchondromatosis and an intracranial malignancy is rare, but this is because both conditions are relatively rare in themselves(Balcer et al., 1999;Silve and Jüppner, 2006). This combination is not likely to be a coincidence(Ranger et al., 2009a). Moreover, though traditionally it has been thought that Maffucci's syndrome is the more likely syndrome of the two to be associated with a malignancy, in fact, the combination of Ollier's disease and an intracranial malignancy is at least as common, albeit allowing for our lack of knowledge regarding the baseline prevalence rates of OD and MS. Ollier's disease patients also appear to contract their neoplasm at an earlier age, including very young childhood(Ranger et al., 2009b). This is true for both chondrosarcomas and nonsarcomatous neoplasms (NSN). In another study using the same subject pool, for example, patients with OD and malignancy were more than 10 years younger than their MS counterparts $(24.7$ vs. 34.9 years; $p=0.002)$, as were patients with OD and chondrosarcoma versus those with MS and chondrosarcoma $(24.7$ vs. $36.2 ; \mathrm{p}=$ 0.035)(Ranger et al., 2009a). Among those with NSN, the difference in mean age approached statistical significance $(24.7$ vs. 32.6; $\mathrm{p}=0.092)$. Also, seven of 24 with OD were 18 years old or younger, versus just 2 of 22 with MS.

However, other than youths tending towards being more likely to have the combination of OD and malignancy than MS and malignancy, no other significant differences seem to exist between youths and adults, with respect to the demographic characteristics of patients or the clinical characteristics of their intracranial tumours(Ranger and Szymczak, 2009). What this implies is that the underlying enchondromatosis is associated with at least a reasonably lifelong increased risk of malignancy, which persists into the sixth decade, if not beyond, rather than there being distinct characteristics of childhood/adolescence and adulthood that predispose such patients to risk.

What causes that persistent increase in malignancy potential is not yet known. We do know that single enchondromas, outside some greater syndrome, are associated with an elevated risk of malignant change. Altay et al(Altay et al., 2007), for example, conducted an 18-year retrospective analysis of 627 cartilage-forming benign bone tumours, and found that 32 patients had experienced malignant transformation, with 14 of these 32 patients initially having had a solitary osteochondroma, ten multiple osteochondromas, six a solitary enchondroma, one Ollier's disease, and one Maffucci's syndrome. The one patient with Ollier's disease had two chondrosarcomas; and the single patient with multiple osteochondroma had three chondrosarcomas. The overall rate of malignant transformation for cartilage-originating tumours was $5.1 \%$, being $4.2 \%$ for solitary osteochondromas, $9.2 \%$ for multiple osteochondromas, and $4.2 \%$ for solitary enchondromas.

A variety of chromosomal abnormalities also have been reported in isolated cases of OD or MS and chondrosarcoma. These abnormalities include, for example, the interstitial deletion, $\operatorname{del}(1)(p 11 p 31.2)$, as the only chromosomal abnormality identified in a low-grade chondrosarcoma in a patient with Ollier's disease(Ozisik et al., 1998). Also, Bovée et al(Bovee et al., 2000) identified (1) the loss of heterozygosity (LOH) in a tibial chondrosarcoma and its 
metastases, exclusively on chromosome bands 13q14 and 9p21, with the LOH not identified in a femoral enchondroma that was analyzed; and (2) p53 over-expression in a tibial chondrosarcoma and its metastases, not present in a femoral enchondroma. Meanwhile, Chang et al(Chang and Prados, 1994) identified identical male twins with OD who both developed astrocytomas within their cerebral cortex during their early twenties; and Robinson et al(Robinson et al., 1994) found evidence of mitogenic neurotransmitters within both enchondromas and soft tissue hemangiomas in a patient with Maffucci's syndrome, implying that the bone and vascular lesions, and possibly malignant tumours, might be related to an underlying neural abnormality. Having said all this, to date, no consistent chromosomal abnormalities have been identified in these patients, and all theories regarding the cause of malignancies in these syndromes remain unproven.

Just like the phakomatoses and familial syndromes like Li-Fraumeni and Turcot syndrome, enchondromatosis appears to confer a substantial increased risk of a variety of CNS and other malignancies, at least through the sixth decade of life and as early as the first decade; and children, adolescents and adults appear not to differ substantially in this risk. These two points have implications for both primary physicians and specialists, including surgeons; because it means that the risk of intracranial malignancy should not be ignored in any patient with enchondromatosis, whether they have accompanying vascular lesions or not. In fact, those without vascular lesions may have higher risk over the first few decades of life than those with. Ideally, further research one day will clarify the cause or causes of this increased risk. Moreover, as we gain a better understanding of the genetics behind the various familial disorders associated with malignancy, improved and more precisely targeted therapies will be developed, to more successfully treat malignancies once they arise, and perhaps even to prevent them in those who are at significantly increased risk.

\section{References}

(2008) Enchondromatosis: In The Free Dictionary by Farlex at http://medicaldictionary.thefreedictionary.com/enchondromatosis. In.

Ahmed,S.K., Lee,W.C., Irving,R.M., Walsh,A.R. (1999) Is Ollier's disease an understaging of Maffucci's syndrome? J Laryngol Otol 113(9): 861-864.

Alaraj,A.M., Valyi-Nagy,T., Roitberg,B. (2007) Double phakomatosis; neurofibromatosis type-1 and tuberous sclerosis. Acta Neurochir (Wien). 149(5): 505-509.

Altay,M., Bayrakci,K., Yildiz,Y., Erekul,S., Saglik,Y. (2007) Secondary chondrosarcoma in cartilage bone tumors: report of 32 patients. J Orthop Sci 12(5): 415-423.

Amlashi,S.F., Riffaud,L., Brassier,G., Morandi,X. (2003) Nevoid basal cell carcinoma syndrome: relation with desmoplastic medulloblastoma in infancy. A populationbased study and review of the literature. Cancer 98(3): 618-624.

Arfan-ul-Bari,S.-R. (2003) Segmental neurofibromatosis [NF type - v]. J Coll Physicians Surg Pak. 13(12): 717-718.

Arun,D., Gutmann,D.H. (2004) Recent advances in neurofibromatosis type 1. Curr Opin Neurol. 17(2): 101-105.

Balasundrum,S., Kovilpillai,F.J., Hopper,C. (2010) Nevoid basal cell carcinoma syndrome presenting with neck pits and café au lait patches. J Clin Pediatr Dent. 35(1): 95-100.

Balcer,L.J., Galetta,S.L., Cornblath,W.T., Liu,G.T. (1999) Neuro-ophthalmologic manifestations of Maffucci's syndrome and Ollier's disease. J Neuroophthalmol 19(1): $62-66$. 
Bance,M., Ramsden,R.T. (1999) Management of neurofibromatosis type 2. Ear Nose Throat J. 78(2): 91-94, 96.

Baser,M.E., R Evans,D.G., Gutmann,D.H. (2003) Neurofibromatosis 2. Curr Opin Neurol. 16(1): 27-33.

Baujat,B., Krastinova-Lolov,D., Blumen,M., Baglin,A.C., Coquille,F., Chabolle,F. (2006) Radiofrequency in the treatment of craniofacial plexiform neurofibromatosis: a pilot study. Plast Reconstr Surg. 117(4): 1261-1268.

Baumgart,R., Bürklein D, Hinterwimmer,S., Thaller,P., Mutschler,W. (2005) The management of leg-length discrepancy in Ollier's disease with a fully implantable lengthening nail. J Bone Joint Surg Br 87(7): 1000-1004.

Bertucci,V., Krafchik,B.R. (1995) What syndrome is this? Ollier disease + vascular lesions: Maffucci syndrome. Pediatr Dermatol 12(1): 55-8.

Birch,J.M. (1994) Li-Fraumeni syndrome. Eur J Cancer 30A(13): 1935-1941.

Birch,J.M., Alston,R.D., McNally,R.J., et al. (2001) Relative frequency and morphology of cancers in carriers of germline TP53 mutations. Oncogene 20(34): 4621-4628.

Boinet,E. (1904) Enchondrose rachitiforme. Arch Gen de Med 194: 2689-2717.

Boman,K.K., Hoven,E., Anclair,M., Lannering,B., Gustafsson,G. (2009) Health and persistent functional late effects in adult survivors of childhood CNS tumours: a populationbased cohort study. Eur J Cancer 45(14): 2552-2561.

Bondy,M., Wiencke,J., Wrensch,M., Kyritis,A.P. (1994) Genetics of primary brain tumors: a review. J Neurooncol. 18(1): 69-81.

Bovee,J.V.M.G., Graadt van Roggen,J.F., Cleton-Jansen,A.M., Taminiau,A.H.M., Woude,H.J., van der Hogendoorn,P.C.W. (2000) Malignant progression in multiple enchondromatosis (Ollier"s disease): An autopsy-based molecular genetic study. Human Pathol 31(10): 1299-1303.

Bunin,G.R., Feuer,E.J., Witman,P.A., Meadows,A.T. (1996) Increasing incidence of childhood cancer: report of 20 years experience from the greater Delaware Valley Pediatric Tumor Registry. Paediatr Perinat Epidemiol 10(3): 319-338.

Burton,B.J., Kumar,V.G., Bradford,R. (1997) Granular cell tumour of the spinal cord in a patient with Rubenstein-Taybi syndrome. Br J Neurosurg. 11(3): 257-259.

Butman,J.A., Linehan,W.M., Lonser,R.R. (2008) Neurologic manifestations of von HippelLindau disease. JAMA 300(11): 1334-1342.

Centers for Disease Control and Prevention (CDC) (2007) Trends in childhood cancer mortality--United States, 1990-2004. MMWR Morb Mortal Wkly Rep. 56(48): 12571261.

Chang,S., Prados,M.D. (1994) Identical twins with Ollier's disease and intracranial gliomas: case report. Neurosurg 34(5): 903-906.

Chatenoud,L., Bertuccio,P., Bosetti,C., Levi,F., Negri,E., La Vecchia,C. (2010) Childhood cancer mortality in America, Asia, and Oceania, 1970 through 2007. Cancer 116(21): 5063-5074.

Cheng,L., Scheithauer,B.W., Leibovich,B.C., Ramnani,D.M., Cheville,J.C., Bostwick,D.G. (1999) Neurofibroma of the urinary bladder. Cancer 86(3): 505-513.

Cherqui,A., Kim,D.H., Kim,S.H., Park,H.K., Kline,D.G. (2007) Surgical approaches to paraspinal nerve sheath tumors. Neurosurg Focus 22(6): E9.

Committee on Genetics (1995) Health Supervision for children with neurofibromatosis. Pediatrics 96: 368-372. 
Crowe,F.W., Schull,W.J., Neel,J.V. (1956) Crowe FW, Schull WJ, Nee1 JV. A clinical, pathological and genetic study of multiple neurofibromatosis. Springfield, IL.

Crump,T. (1981) Translation of case reports in Ueber die multiplen Fibrome der Haut und ihre Beziehung zu den multiplen Neuromen by F. v. Recklinghausen. Adv Neurol. 29: 259-275.

Dang,J.D., Cohen,P.R. (2010) Segmental neurofibromatosis and malignancy. Skinmed. 8(3): 156-159.

Deb,P., Gupta,A., Sharma,M.C., Gaikwad,S., Singh,V.P., Sarkar,C. (2006) Meningioangiomatosis with meningioma: an uncommon association of a rare entity--report of a case and review of the literature. Childs Nerv Syst. 22(1): 78-83.

DeBella,K., Szudek,J., Friedman,J.M. (2000) Use of the National Institutes of Health criteria for diagnosis of neurofibromatosis 1 in children. Pediatrics 105: 608-614.

Denckla,M.D., Hofman,K., Mazzocco,M.M.M., et al. (1996) Relationship between T2weighted hyperintensities (unidentified bright objects)and lower IQs in children with neurofibromatosis-1. Am J Med Genet. 67: 98-102.

Dodge,H.W., Lowe,J.G., Craig,W.M., et al. (1958) Gliomas of the optic nerves. Arch.Neurol.Psychiatr. 79: 607-621.

Ellenberg,L., Liu,Q., Gioia,G., Yasui,Y., Packer,R.J., Mertens,A., Donaldson,S.S., Stovall,M., Kadan-Lottick,N., Armstrong,G., Robison,L.L., Zeltzer,L.K. (2009) Neurocognitive status in long-term survivors of childhood CNS malignancies: a report from the Childhood Cancer Survivor Study. Neuropsychology 23(6): 705-717.

Ellison,L.F., De,P., Mery,L.S., Grundy,P.E., Canadian Cancer Society's Steering Committee for Canadian Cancer Statistics. (2009) Canadian cancer statistics at a glance: cancer in children. CMAJ.2009 Feb 17;180(4):422-4. 180(4): 422-424.

Evans,D.G. (1999) Neurofibromatosis type 2: genetic and clinical features. Ear Nose Throat J. 78(2): 97-100.

Evans,D.G., Famdon,P.A., Burnell,L.D., Gattamaneni,H.R., Birch,J.M. (1991) The incidence of Gorlin syndrome in 173 consecutive cases of medulloblastoma. Br J Cancer 64(5): 959-961.

Evans,D.G., Howard,E., Giblin,C., et al. (2010) Birth incidence and prevalence of tumour prone syndromes: estimates from a UK genetic family register service. Am J Med Genet. 152A: 327-332.

Evans,D.G., Ramsden,R.T., Gokhale,C., Bowers,N., Huson,S.M., Wallace,A. (2007) Should NF2 mutation screening be undertaken in patients with an apparently isolated vestibular schwannoma? Clin Genet. 71(4): 354-358.

Evans,D.G., Wu,C.L., Birch,J.M. (2008) BRCA2: a cause of Li-Fraumeni-like syndrome. J Med Genet. 45: 62-63.

Ferner,R.E. (2007) Neurofibromatosis 1 and neurofibromatosis 2: a twenty first century perspective. Lancet Neurol. 6(4): 340-351.

Ferner,R.E. (2010) The neurofibromatoses. Pract Neurol. 10(2): 82-93.

Ferner,R.E., Huson,S.M., Thomas,N., Moss,C., Willshaw,H., Evans,D.G., Upadhyaya,M., Towers,R., Gleeson,M., Steiger,C., Kirby,A. (2007) Guidelines for the diagnosis and management of individuals with neurofibromatosis 1. J Med Genet. 44(2): 81-8.

Fontaine,B., Hanson,M.P., VonSattel,J.P., et al. (1991a) Loss of chromosome 22 alleles in human sporadic spinal schwannomas. Ann Neurol. 29(2): 183-186. 
Fontaine,B., Sanson,M., Delattre,O., et al. (1991b) Parental origin of chromosome 22 loss in sporadic and NF2 neuromas. Genomics 10(1): 280-283.

Foulkes,W.D. (1995) A tale of four syndromes: familial adenomatous polyposis, Gardner syndrome, attenuated APC and Turcot syndrome. QJM 88(12): 853-863.

Franz,D.N., Leonard,J., Tudor,C., et al. (2006) Rapamycin causes regression of astrocytomas in tuberous sclerosis complex. Ann Neurol. 59(3): 490-498.

Giuffré,R., Bardelli,A.M., Taverniti,L., Barberi,I. (1982) Anterior optic pathways glioma. The dilemma of treatment. J.Neurosurg.Sci. 26: 61-72.

Glasker,S. (2005) Central nervous system manifestations in VHL: genetics, pathology and clinical phenotypic features. Fam Cancer 4(1): 37-42.

Goh,S., Butler,W., Thiele,E.A. (2004) Subependymal giant cell tumors in tuberous sclerosis complex. Neurology 63(8): 1457-1461.

Grajkowska,W., Kotulska,K., Jurkiewicz,E., Matyja,E. (2010) Brain lesions in tuberous sclerosis complex. Review. Folia Neuropathol. 48(3): 139-149.

Greig,A.V., Kirkpatrick,N.A., Joshi,N., Kelly,M., Waterhouse,N. (2009) Giant hemifacial plexiform neurofibroma arising from trigeminal ganglion. J Craniofac Surg. 20(3): 833-836.

Gutmann,D.H., Aylsworth,A., Carey,J.C., et al. (1997) The diagnostic evaluation and multidisciplinary management of neurofibromatosis 1 and neurofibromatosis 2 . JAMA 278(1): 51-57.

Hager,C.M., Cohen,P.R., Tschen,J.A. (1997) Segmental neurofibromatosis: case reports and review. J Am Acad Dermatol. 37((5 Pt 2)): 864-869.

Hahn,J.S., Chung,J.B., Han,S.H., Lee,S.W., Noh,S.H., Lee,J.T., Chun,S.I., Kim,S.H. (1992) Intestinal neurofibromatosis in von Recklinghausen's disease: presenting as chronic anemia due to recurrent intestinal hemorrhage. Korean J Intern Med. 7(2): 137-142.

Hamilton,S.R., Liu,B., Parsons,R.E., et al. (1995) The molecular basis of Turcot's syndrome. $N$ Engl J Med. 332(13): 839-847.

Hanada,M., Tanaka,T., Kanayama,S., Takami,M., Kimura,M. (1982) Malignant transformation of intrathoracic ancient neurilemoma in a patient without von Recklinghausen's disease. Acta Pathol Jpn. 32(3): 527-536.

Harrison,J.E., Bolton,P.F. (1997) Annotation: Tuberous sclerosis. J Child Psychol Psychiatry 38(6): 603-614.

Hassard,A.D., Boudreau,S.F., Cron,C.C. (1984) Adenoma of the endolymphatic sac. J Otolaryngol. 13: 213-216.

Hersh,J.H., American Academy of Pediatrics Committee on Genetics (2008) Health supervision for children with neurofibromatosis. Pediatrics 121(3): 633-642.

Hes,F.J., van der Luitj,R.B., Lips,C.J. (2001) Clinical management of Von Hippel-Lindau (VHL) disease. Neth J Med. 59(5): 225-234.

Hong,C.H., Darling,T.N., Lee,C.H. (2009) Prevalence of tuberous sclerosis complex in Taiwan: a national population-based study. Neuroepidemiology 33(4): 335-341.

Hottinger,A.F., Khakoo,Y. (2009a) Neuro-oncology of Neurofibromatosis Type 1. Curr Treat Options Neurol. 11(4): 306-314.

Hottinger,A.F., Khakoo,Y. (2009b) Neurooncology of familial cancer syndromes. J Child Neurol.. 24(12): 1526-1535.

Huson,S.M., Harper,P.S., Compston,D.A. (1988) Von Recklinghausen neurofibromatosis. A clinical and population study in south-east Wales. Brain 111((Pt 6)): 1355-1381. 
Hyman,S.L., Gill,D.S., Shores,E.A., Steinberg,A., Joy,P., Gibikote,S.V., North,K.N. (2003) Natural history of cognitive deficits and their relationship to MRI T2hyperintensities in NF1. Neurology 60(7): 1139-1145.

Jackson,I.T. (2001) Management of craniofacial neurofibromatosis. Facial Plast Surg Clin North Am. 9(1): 59-75.

Jacoby,L.B., MacCollin,M., Parry,D.M., et al. (1999) Allelic expression of the NF2 gene in neurofibromatosis 2 and schwannomatosis. Neurogenetics 2(2): 101-108.

Jacquemin,C., Bosley,T.M., Svedberg,H. (2003) Orbit deformities in craniofacial neurofibromatosis type 1. AJNR Am J Neuroradiol. 24(8): 1678-1682.

Jallo,G.I., Kothbauer,K., Mehta,V., Abbott,R., Epstein,F. (2005) Meningioangiomatosis without neurofibromatosis: a clinical analysis. J Neurosurg. 103((4 Suppl)): 319-324.

Jamjoom,Z.A., Sadiq,S., Mofti,A.B., al-Mofleh,I., Ajarim,D. (1989) Turcot syndrome: report of a case and review of the literature. Int Surg. 74(1): 45-50.

Joy,P., Roberts,C., North,K.N., de Silva,M. (1995) Neuropsychological function and MRI abnormalities in neurofibromatosis type 1. Dev Med Child Neurol. 37(10): 906-914.

Kaefer,M., Adams,M.C., Rink,R.C., Keating,M.A. (1997) Principles in management of complex pediatric genitourinary plexiform neurofibroma. Urology 49(6): 936-940.

Kast,A., von Recklinghausen,F.D. (1889) Ein Fall von Enchondrom mit ungewöhnlicher Multiplikation. Virchows Archiv für pathologische Anatomie und Physiologie und für klinische Medicin, Berlin 118: 1-118.

Khong,P.L., Goh,W.H., Wong,V.C., Fung,C.W., Ooi,G.C. (2003) MR imaging of spinal tumors in children with neurofibromatosis 1. AJR Am J Roentgenol. 180(2): 413-417.

Kleihues,P., Schauble,B., zur Hausen,A., Esteve,J., Ohgaki,H. (1997) Tumors associated with p53 germline mutations: a synopsis of 91 families. Am J Pathol. 150(1): 1-13.

Koeller,K.K., Rosenblum,R.S., Morrison,A.L. (2000) Neoplasms of the spinal cord and filum terminale: radiologic-pathologic correlation. Radiographics 20(6): 1721-1749.

Korf,B.R. (1999) Plexiform neurofibromas. Am J Med Genet. 89(1): 31-37.

Korf,B.R. (2005) The phakomatoses. Clin Dermatol. 23(1): 78-84.

Legendre,C.M., Charpentier-Cote,C., Drouin,R., Bouffard,C. (2011) Neurofibromatosis type 1 and the "elephant man's" disease: the confusion persists: an ethnographic study. PLoS One 6(2): e16409.

Leonard,J.R., Perry,A., Rubin,J.B., et al. (2006) The role of surgical biopsy in the diagnosis of glioma in individuals with neurofibromatosis-1. Neurology 67(8): 1509-1512.

Li,F.P., Fraumeni,J.F.J., Mulvihill,J.J., et al. (1988) A cancer family syndrome in twenty-four kindreds. Cancer Res. 48(18): 5358-5362.

Linet,M.S., Ries,L.A., Smith,M.A., Tarone,R.E., Devesa,S.S. (1999) Cancer surveillance series: recent trends in childhood cancer incidence and mortality in the United States. J Natl Cancer Inst 91(12): 1051-1058.

Lopes Ferraz Filho,J.R., Munis,M.P., Soares Souza,A., Sanches,R.A., Goloni-Bertollo,E.M., Pavarino-Bertelli,E.C. (2008) Unidentified bright objects on brain MRI in children as a diagnostic criterion for neurofibromatosis type 1. Pediatr Radiol. 38(3): 305-310.

Lu-Emerson,C., Plotkin,S.R. (2009a) The Neurofibromatoses. Part 1: NF1. Rev Neurol Dis. 6(2): E47-E53.

Lu-Emerson,C., Plotkin,S.R. (2009b) The neurofibromatoses. Part 2: NF2 and schwannomatosis. Rev Neurol Dis. 6(3): E81-E86. 
Maffucci,A. (1881) Di un caso encondroma ed angioma multiplo. Contribuzione alla genesi embrionale dei tumori. Movimento medico-chirurgico, Napoli, 1881, 3: 399-412 and 565-575. 3: 399-412-565-575.

Mansur,A.T., Goktay,F., Akkaya,A.D., Gunes,P. (2011) Segmental neurofibromatosis: report of 3 cases. Cutis 87(1): 45-50.

Massimi,L., Tufo,T., Rocco,C. (2007) Management of optic-hypothalamic gliomas in children: still a challenging problem. Expert Rev Anticancer Ther. 7(11): 1591-1610.

McLaughlin,M.R., Gollin,S.M., Lese,C.M., Albright,A.L. (1998) Medulloblastoma and glioblastoma multiforme in a patient with Turcot syndrome: a case report. Surg Neurol. 49(3): 295-301.

Mellon,C.D., Carter,J.E., Owen,D.B. (1988) Ollier's disease and Maffucci's syndrome: distinct entities or a continuum. Case report: enchondromatosis complicated by an intracranial glioma. J Neurol 235(6): 376-378.

Morais,P., Ferreira,O., Bettencourt,H., Azevedo,F. (2010) Segmental neurofibromatosis: A rare variant of a common genodermatosis. Acta Dermatovenerol Alp Panonica Adriat. 19(3): 27-29.

Morrison,P.J. (2009) Tuberous sclerosis: epidemiology, genetics and progress towards treatment. Neuroepidemiology 33(4): 343.

Neurofibromatosis Conference Statement (1988) National Institutes of Health. Consensus Development Conference. Arch Neurol. 45(5): 575-578.

NF1 Cognitive Disorders Task Force. (1997) Cognitive function and academic performance in neurofibromatosis 1. Neurology 48: 1121-1127.

Niemela,M., Lemeta,S., Summanen,P., Bohling,T., Sainio,M., Kere,J., et al. (1999) Long-term prognosis of haemangioblastoma of the CNS: impact of von Hippel-Lindau disease. Acta Neurochir (Wien). 141(11): 1147-1156.

North,K.N., Joy,P., Yuille,D., Cocks,N., Hutchins,P. (1995) Cognitive function and academic performance in children with neurofibromatosis type 1. Dev Med Child Neurol. 37(5): 427-436.

North,K.N., Joy,P., Yuille,D., Cocks,N., Mobbs,E., Hutchins,P., McHugh,K., de Silva,M. (1994) Specific learning disability in children with neurofibromatosis type 1: significance of MRI abnormalities. Neurology 44(5): 878-883.

North,K.N., Riccardi,V., Samango-Sprouse,C., Ferner,R.E., Moore,B., Legius,E., Ratner,N., Denckla,M.B. (1997) Cognitive function and academic performance in neurofibromatosis. 1: consensus statement from the NF1 Cognitive Disorders Task Force. Neurology 48(4): 1121-1127.

Oh,K.S., Hung,J., Robertson,P.L., Garton,H.J., Muraszko,K.M., Sandler,H.M., Hamstra,D.A. (2011) Outcomes of Multidisciplinary Management in Pediatric Low-Grade Gliomas. Int J Radiat Oncol Biol Phys.2011 Apr 4.[Epub ahead of print].

Ollier,L. (1899) Dyschondroplasia [Italian]. Bull Soc Lyon Med 93: 23-24.

Omeis,I., Hillard,V.H., Braun,A., Benzil,D.L., Murali,R., Harter,D.H. (2006) Meningioangiomatosis associated with neurofibromatosis: report of 2 cases in a single family and review of the literature. Surg Neurol. 65(6): 595-603.

Ong,K.R., Woodward,E.R., Killick,P., Lim,C., Macdonald,F., Maher,E.R. (2007) Genotypephenotype correlations in von Hippel-Lindau disease. Hum Mutat. 28(2): 143-149.

Orlova,K.A., Crino,P.B. (2010) The tuberous sclerosis complex. Ann N Y Acad Sci. 1184(Jan): 87-105. 
Osborne,J.P., Fryer,A., Webb,D. (1991) Epidemiology of tuberous sclerosis. Ann NY Acad Sci. 615: 125-127.

Ozisik,Y., Meloni,A.M., Spanier,S.S., Bush,C.H., Kingsley,K.L., Sandberg,A.A. (1998) Deletion $1 \mathrm{p}$ in a low-grade chondrosarcoma in a patient with Ollier disease. Canc Genet Cytogen 105(2): 128-133.

Paraf,F., Jothy,S., Van Meir,E.G. (1997) Brain tumor-polyposis syndrome: two genetic diseases? J Clin Oncol. 15(7): 2744-2758.

Park,B.Y., Hong,J.P., Lee,W.J. (2002) Netting operation to control neurofibroma of the face. Plast Reconstr Surg. 109(4): 1228-1237.

Pearce,J.M.S. (2003) Historical Note: Neurofibromatosis. J Neurol Neurosurg Psychiatry 74(3): 384.

Poussaint,T.Y., Barnes,P.D., Nichols,K., et al. (1997) Diencephalic syndrome: clinical features and imaging findings. Am.J.Neuroradiol. 18: 1499-1505.

Ranger,A., Szymczak,A. (2009) The association between intracranial tumours and multiple dyschondroplasia (Ollier's disease or Maffucci's syndrome): do children and adults differ? J Neurooncol. 95(2): 165-173.

Ranger,A., Szymczak,A., Hammond,R., Zelcer,S. (2009a) Do intracranial neoplasms differ in Ollier's disease and Maffucci's syndrome? - An in-depth analysis of the literature. [in press]. Neurosurgery.

Ranger,A., Szymczak,A., Hammond,R., Zelcer,S. (2009b) Pediatric thalamic glioblastoma associated with Ollier's disease (multiple enchondromatosis): a rare case of concurrence. J Neurosurg Pediatr. 4(4): 363-367.

Rendón-Macías,M.E., Ramos-Becerril,C., Bernardez-Zapata,I., Iglesias-Leboreiro,J. (2008) [Cancer epidemiology in children and adolescents at private health care (19952004)] [Article in Spanish]. Rev Med Inst Mex Seguro Soc 46(4): 353-360.

Richard,S., Campello,C., Taillandier,L., Parker,F., Resche,F. (1998) Haemangioblastoma of the central nervous system in von Hippel-Lindau disease. French VHL Study Group. J Intern Med. 243(6): 547-553.

Ridler,K., Suckling,J., Higgins,N.J., de Vries,P.J., Stephenson,C.M.E., Bolton,P.F., Bullmore,E.T. (2006) Neuroanatomical Correlates of Memory Deficits in Tuberous Sclerosis Complex. Cerebral Cortex 17(2): 261-271.

Rieley,M.B., Stevenson,D.A., Viskochil,D.H., Tinkle,B.T., Martin,L.J., Schorry,E.K. (2011) Variable expression of neurofibromatosis 1 in monozygotic twins. Am J Med Genet A.2011 Feb 18.doi: 10.1002/ajmg.a.33851.[Epub ahead of print].

Roaches,E.S., Gomez,M.R., Northrup,H. (1998) Tuberous sclerosis complex consensus conference: revised clinical diagnostic criteria. J Child Neurol. 13(12): 624-628.

Robinson,D., Tieder,M., Halperin,N., Burshtein,D., Nevo,Z. (1994) Maffucci's syndrome--the result of neural abnormalities? Evidence of mitogenic neurotransmitters present in enchondromas and soft tissue hemangiomas. Cancer 74(3): 949-957.

Sarica,F.B., Cekinmez,M., Tufan,K., Erdogan,B., Sen,O., Altinors,M.N. (2008) A rare case of massive NF1 with invasion of entire spinal axis by neurofibromas: case report. Turk Neurosurg. 18(1): 99-106.

Satter,E. (2007) Proteus syndrome: 2 case reports and a review of the literature. Cutis. 80(4): 297-302. 
Schimke,R.N., Collins,D.L., Stolle,C.A. (2009) Von Hippel-Lindau Syndrome.Schimke RN, Collins DL, Stolle CA. In: Pagon,R.A., Bird,T.D., Dolan,C.R., Stephens,K. (eds) GeneReviews [Internet], Seattle (WA): University of Washington, Seattle.

Schroder,S., Moehrs,D., von Weltzien,J., Winkler,R., Otto,H.F. (1983) The Turcot syndrome. Report of an additional case and review of the literature. Dis Colon Rectum 26(8): 533-538.

Schwartz,H.S., Zimmerman,N.B., Simon,M.A., Wroble,R.R., Millar,E.A., Bonfiglio,M. (1987) The malignant potential of enchondromatosis. J Bone Joint Surg Am 69(2): 269-274.

Seizinger,B.R., Rouleau,G.A., Ozelius,L.J., et al. (1988) Von Hippel-Lindau disease maps to the region of chromosome 3 associated with renal cell carcinoma. Nature 332(6161): 268-269.

Sezer,E., Senayli,A., Sezer,T., Bicakci,U. (2006) Segmental neurofibromatosis: report of two cases. J Dermatol. 33(9): 635-638.

Shanley,S., Ratcliffe,J., Hockey,A., et al. (1994) Nevoid basal cell carcinoma syndrome: review of 118 affected individuals. Am J MedGenet. 50(3): 282-290.

Shapiro,F. (1982) Ollier's Disease. An assessment of angular deformity, shortening, and pathological fracture in twenty-one patients. J Bone Joint Surg Am.1982 Jan;64(1):95103. 64(1): 95-103.

Silve,C., Jüppner,H. (2006) Ollier disease. Orphanet J Rare Dis.2006 Sep 22;1:37. 1: 37.

Stavrou,T., Bromley,C.M., Nicholson,H.S., et al. (2001) Prognostic factors and secondary malignancies in childhood medulloblastoma. J Pediatr Hematol Oncol. 23(7): 431-436.

Tago,M., Terahara,A., Shin,M., Maruyama,K., Kurita,H., Nakagawa,K., Ohtomo,K. (2005) Gamma knife surgery for hemangioblastomas. J Neurosurg. 102(Suppl.): 171-174.

Taipale,J., Chen,J.K., Cooper,M.K., et al. (2000) Effects of oncogenic mutations in Smoothened and Patched can be reversed by cyclopamine. Nature 406(6799): 10051009.

Taylor,M.D., Mainprize,T.G., Rutka,J.T. (2000) Molecular insight into medulloblastoma and central nervous system primitive neuroectodermal tumor biology from hereditary syndromes: a review. Neurosurgery 47(4): 888-901.

Taylor,M.D., Mainprize,T.G., Rutka,J.T., Becker,L., Bayani,J., Drake,J.M. (2001) Medulloblastoma in a child with Rubenstein-Taybi Syndrome: case report and review of the literature. Pediatr Neurosurg. 35(5): 235-238.

Thayer,S.P., di Magliano,M.P., Heiser,P.W.e.al. (2003) Hedgehog is an early and late mediator of pancreatic cancer tumorigenesis. Nature 425(6960): 851-856.

Valdueza,J.M., Cristante,L., Dreitag,J., Hagel,C., Hermann,H.D. (1995) Malignant chiasmal glioma: a rare cause of rapid visual loss. Neurosurg.Rev. 18: 273-275.

Van der Hoeve,J. (1920) Eye symptoms in tuberous sclerosis of the brain. Trans Ophthalmol Soc UK. 40: 329-334.

Verma,K.K., Ovung,E.M., Sirka,C.S. (2001) Extensive facial angiofibromas in tuberous sclerosis treated with carbon dioxide laserbrasion. Dermato Surg. 67(6): 326-328.

Visrutaratna,P., Oranratanachai,K., Singhavejsakul,J. (2004) Clinics in diagnostic imaging (96). Plexiform neurofibromatosis. Singapore Med J. 45(4): 188-192.

Wanebo,J.E., Lonser,R.R., Glenn,G.M., Oldfield,E.H. (2003) The natural history of hemangioblastomas of the central nervous system in patients with von HippelLindau disease. J Neurosurg. 98(1): 82-94. 
Wang,E.M., Pan,L., Wang,B.J., Zhang,N., Zhou,L.F., Dong,Y.F., Dai,J.Z., Cai,P.W., Chen,H. (2005) The long-term results of gamma knife radiosurgery for hemangioblastomas of the brain. J Neurosurg. 102(Suppl.): 225-229.

Wixom,C., Chadwick,A.E., Krous,H.F. (2005) Sudden, unexpected death associated with meningioangiomatosis: case report. Pediatr Dev Pathol. 8(2): 240-244.

Woodruff,J.M. (1999) Pathology of tumors of the peripheral nerve sheath in type 1 neurofibromatosis. Am J Med Genet. 89(1): 23-30.

Zhang,H., Cai,C., Wang,S., Liu,H., Ye,Y., Chen,X. (2007) Extracranial head and neck schwannomas: a clinical analysis of 33 patients. Laryngoscope 117(2): 278-281. 


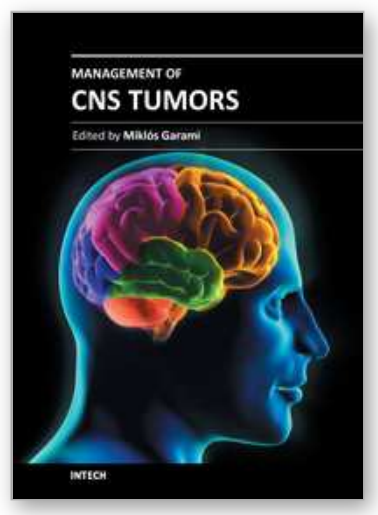

\author{
Management of CNS Tumors \\ Edited by Dr. Miklos Garami
}

ISBN 978-953-307-646-1

Hard cover, 464 pages

Publisher InTech

Published online 22, September, 2011

Published in print edition September, 2011

Management of CNS Tumors is a selected review of Central Nervous System (CNS) tumors with particular emphasis on pathological classification and complex treatment algorithms for each common tumor type. Additional detailed information is provided on selected CNS tumor associated disorders.

\title{
How to reference
}

In order to correctly reference this scholarly work, feel free to copy and paste the following:

Adrianna Ranger (2011). Syndromes Associated with Intracranial Tumours: A Paediatric Neurosurgeon's Perspective, Management of CNS Tumors, Dr. Miklos Garami (Ed.), ISBN: 978-953-307-646-1, InTech, Available from: http://www.intechopen.com/books/management-of-cns-tumors/syndromes-associated-withintracranial-tumours-a-paediatric-neurosurgeon-s-perspective

\section{INTECH}

open science | open minds

\section{InTech Europe}

University Campus STeP Ri

Slavka Krautzeka 83/A

51000 Rijeka, Croatia

Phone: +385 (51) 770447

Fax: +385 (51) 686166

www.intechopen.com

\section{InTech China}

Unit 405, Office Block, Hotel Equatorial Shanghai

No.65, Yan An Road (West), Shanghai, 200040, China

中国上海市延安西路65号上海国际贵都大饭店办公楼405单元

Phone: +86-21-62489820

Fax: $+86-21-62489821$ 
(C) 2011 The Author(s). Licensee IntechOpen. This chapter is distributed under the terms of the Creative Commons Attribution-NonCommercialShareAlike-3.0 License, which permits use, distribution and reproduction for non-commercial purposes, provided the original is properly cited and derivative works building on this content are distributed under the same license. 